\title{
Effects of climate change on maize production, and potential adaptation measures: a case study in Jilin Province, China
}

\author{
Meng Wang ${ }^{1, *}$, Yinpeng Li ${ }^{1,2}$, Wei Ye ${ }^{1}$, Janet F. Bornman ${ }^{1}$, Xiaodong Yan ${ }^{2}$ \\ ${ }^{1}$ International Global Change Centre (IGCC), University of Waikato, Private Bag 3105, Hamilton 3240, New Zealand \\ ${ }^{2}$ START TEA, Institute of Atmospheric Physics, Chinese Academy of Sciences, Beijing 100029, PR China
}

\begin{abstract}
Jilin is among the most important grain-producing provinces in China. Its maize production plays an important role in local and national food security. In this study, we developed a new approach to assess the vulnerability and adaptation options for Jilin maize yields with respect to climate change by modifying a site-based biophysical model to a spatial grid-based application. An ensemble approach that used a combination of 20 general circulation model results and 6 scenarios from the Special Report on Emissions Scenarios was adopted in order to reflect the high uncertainties in future climate projections. The results show that the yield is highly likely to decline in the western and central regions of Jilin but to increase in the east, where maize is not currently grown as the main crop. Phenologically, the growing season will be reduced in the central and western parts, leading to a shortened grain-filling period. The average maize yield in the west and central regions is thus projected to decrease $15 \%$ or more by 2050 as predicted by $90 \%$ of 120 projected scenarios. In addition, $\mathrm{CO}_{2}$ fertilization was investigated and demonstrated a noticeable compensation effect on the yield deduction. However, further field work and/or laboratory-based experiments are required to validate the modeled $\mathrm{CO}_{2}$ fertilization effects. Two potential adaptation strategies, i.e. improving irrigation facilities and introducing cultivars, were identified from the vulnerability assessment and were further tested for the reduction areas. The results revealed that the increase in effective irrigation by upgrading the irrigation system would help to maintain the current production level, but in the long run, the maize cultivars need to be introduced in line with the future warming climate.
\end{abstract}

KEY WORDS: Climate change impacts · Maize production · Scenario uncertainty · Adaptation measures

Resale or republication not permitted without written consent of the publisher

\section{INTRODUCTION}

Food security could be under threat due to the impact of climate change on regional grain production. Effective adaptation measures to alleviate the profound devastating consequences necessitate a regional assessment of crop responses to climate change, in order to identify and evaluate potential adaptation options. Model-based climate change impact assessment methods generally fall into 2 categories: biophysical-based simulations and semi-empirical methods that build on the statistical relationships between crop yield and phenological or environmental variables. The latter is typically used to assess crop sensitivities to climate change (Naylor et al. 2007, Vera-Diaz et al. 2008). Comparatively, the biophysical-based approach has the advantage of including the crop growing processes in its simulation, and hence it is capable of providing insight into the effects of the impact. Jones \& Thornton (2003) applied this method in studying maize production in Africa and Latin America using the CERES-Maize model, in which fine spatial resolution simulations helped to identify highly vulnerable regions to climate change. The CERES model also has a featured capability to assess the quality of adaptations at farm level, such as farm management, but fewer studies have ex- 
plored the effects of adaptation strategies by using process-based models. Using a simplified statistical model, Torriani et al. (2007) conducted sensitivity experiments on the effects of shifts in sowing dates on maize yield under diverse climate-change conditions.

The impact assessment using biophysical crop models can be either site-specific or spatial. The sitespecific application normally focuses on agricultural observation sites, whereas for most of the spatial applications, the impacts are based on the results of several representative sites. For example, Parry et al. (1999) used regional transfer functions that were obtained from site-specific results to calculate the regional/ country-scale crop yield for global food production. Although it is easy to implement and less time consuming to couple the growing process with environmental variables, the method of using a representative site for a large area or area that has complex spatial heterogeneity can lead to significant simulation errors.

Projections of future climate change are characterized by high uncertainties due to the different possible socioeconomic development scenarios, as well as our limited understanding of the climate system. The major sources of uncertainties underlying climate change scenarios include: (1) different $\mathrm{CO}_{2}$ emission levels that are used to project future global warming trends, derived from selfconsistent sets of assumptions about energy use, population growth, economic development, and other factors; and (2) uncertainty corresponding to regional climate change projected by different general circulation models (GCMs; Hulme \& Carter 1999, Katz 2002). Recently, ensemble results consisting of several emission scenarios and multi-GCM outputs have been used to deal with the uncertainties. Tebaldi \& Lobell (2008) adopted a probabilistic analysis to evaluate the uncertainties within the impacts of temperature and precipitation changes from multi-GCM runs on crops at a global level under the Special Report on Emissions Scenarios (SRES) A1B scenario, and Tao et al. (2009) studied the probability distribution of future changes in rice production in northern China by using a super-ensemble of 10 climate scenarios and 5 GCMs.

The objective of our study was not only to present a vulnerability assessment, but also to analyze the potential adaptation options in both crop management and cultivar changes; we therefore adopted a biophysical-based approach. Climate change uncertainty was addressed using a pattern-scaling method, as well as multi-model and multi-scenario simulations.

\section{MATERIALS AND METHODS}

\subsection{Study area}

Jilin Province is located in northeastern China $\left(40^{\circ} 52^{\prime}\right.$ to $46^{\circ} 18^{\prime} \mathrm{N}, 121^{\circ} 38^{\prime}$ to $\left.131^{\circ} 19^{\prime} \mathrm{E}_{\text {; Fig. }} 1\right)$. The total land area is about $187400 \mathrm{~km}^{2}$, which has the highest altitude of around $2000 \mathrm{~m}$ in the southeast and drops gently towards the northwest with the vast Songliao Plain lying in the mid-west of the province. Its climate is dominated by the northerly continental monsoon, and the annual average precipitation varies from $\sim 350 \mathrm{~mm}$ in the northwest to $>1500 \mathrm{~mm}$ in the southeast.

Jilin is the largest commercial grain base of China, producing about $50 \%$ of the commercial maize for the country and $14 \%$ of the total national maize production (China Agriculture Yearbooks 2000-2007, Ministry of Agriculture, China Agriculture Press, Beijing). Maize production accounts for $>70 \%$ of the total grain production of Jilin and occupies $61 \%$ of the crop-sown area, which is mainly in the Songliao Plain in the midwest. The main cropping area is irrigated farmland. The effect of climate change on maize production will be a significant factor determining both future food production in Jilin and the national grain supply.

\subsection{Construction of climate change scenarios}

While it is generally agreed that GCMs are still the best tools for constructing future climate change scenarios, the large variation of simulation results from different GCM runs, or even from the same GCM but with

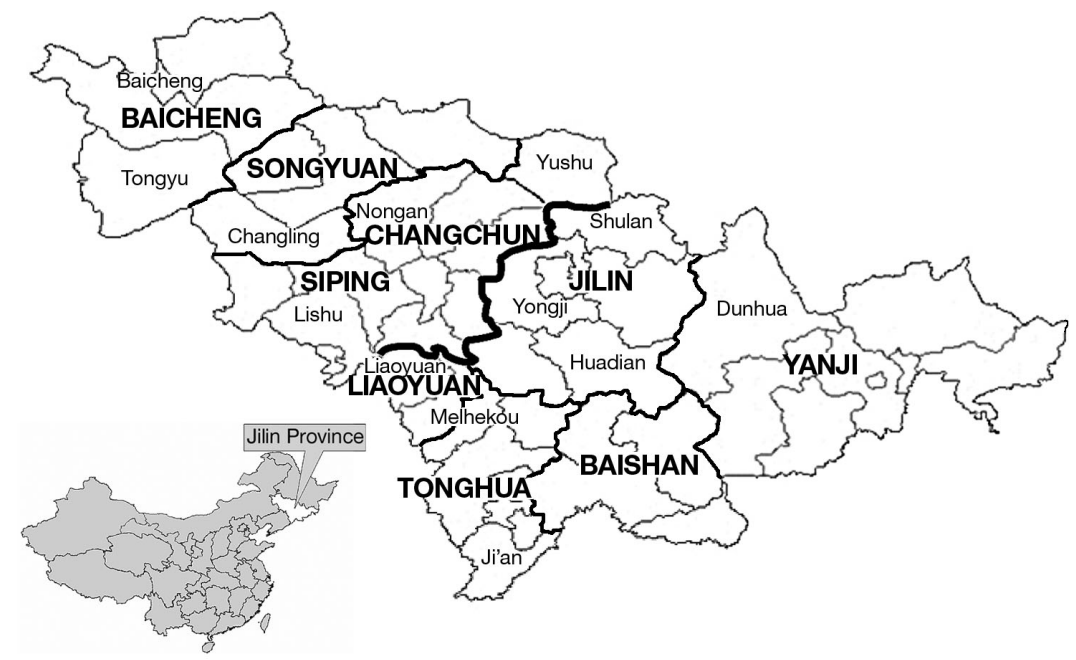

Fig. 1. County and district boundaries of Jilin Province, China. The 9 districts of Jilin are Baicheng, Songyuan, Changchun, Siping, Liaoyuan, Jilin District, Tonghua, Baishan, and Yanji. Late (early) maize cultivars are to the west (east) of the thick black line 
different radiative forcings, has caused great difficulty in applying GCM results directly to climate change impact analyses because the range of uncertainties is an important factor in adaptation planning. Since the early 1990s, an alternative method, known as pattern scaling, has been developed for constructing future climate change scenarios instead of using GCM outputs directly (Santer \& Wigley 1990). Pattern-scaling was originally envisaged as a temporary compromise to add a time component to an equilibrium experiment with a GCM, pending the availability of transient experiments, and also to permit the comparison of standardized spatial patterns from different GCMs (Santer \& Wigley 1990). It offers the possibility of representing the whole range of uncertainties involved in future climate change projections from various combinations of emission scenarios and GCM outputs, which allow cross-model sensitivity analyses and uncertainty examinations to be conducted easily (IPCC-TGICA 2007). The method is recommended by the Intergovernmental Panel on Climate Change (IPCC) for generating the ensemble climate scenarios, with the purpose of dealing with the whole range of future uncertainties (IPCC-TGICA 2007).

The pattern-scaling method is based on the separation of the global mean and spatial pattern components of future climate change. Spatial patterns in the data base are normalized and expressed as changes per $1{ }^{\circ} \mathrm{C}$ change in global mean temperature. These normalized components are appropriately weighted, added, and scaled up to the global mean temperature defined by IPCC SRES for a given year.

Pattern scaling has been widely used in mean temperature and precipitation change studies (Mitchell 2003, Ruosteenoja et al. 2007) and associated impact assessments. Combined with the ensemble approach, New \& Hulme (2000) studied climate change impacts on the river flow in the UK under a full probability of climate change with $7 \mathrm{GCM}$ projections, and Li et al. (2009) studied the risks of global drought disaster using 20 GCMs and 6 SRES scenarios.

For this study, the scenarios of future monthly temperature and precipitation were generated as follows:

$$
\begin{gathered}
T_{1}=T_{0}+\Delta T \times \Delta G M T_{1} \\
P_{1}=P_{0}\left(1+\Delta P / 100 \times \Delta G M T_{1}\right)
\end{gathered}
$$

where $T_{0}\left(T_{1}\right)$ and $P_{0}\left(P_{1}\right)$ are the baseline (future) temperature and precipitation; $\Delta T(\Delta P)$, the change pattern, is the localized change in temperature (precipitation) to per-unit global warming, generated through standardizing the GCM simulation outputs to the corresponding global mean temperature changes; $\triangle G M T$, the scalar, is the change of global mean temperature increase in a future time slice. Details of the pattern scaling method can be found in Mitchell et al. (1999), Mitchell (2003), Wigley (2003), and Li et al. (2009).

To apply the pattern-scaling method to generate climate change scenarios for Jilin Province, the 20 GCM change patterns in the IPCC AR4 Climate Model Intercomparison Project (CMIP; Covey et al. 2003) and 6 SRES (IPCC 2000), i.e. A1B, A1FI, A1T, A2, B1, and B2, were used for the ensemble, with a total ensemble size of 120 scenarios. The GCM change patterns were interpolated from the original resolution of $2.5^{\circ} \times 2.5^{\circ}$ to $5^{\prime} \times 5^{\prime}$ in order to simulate the crop change at the county-level scale, and the years 2020, 2050, and 2070 were selected to assess the impacts of climate change on maize production at different future times. The SRES dataset offers different global warming projections corresponding to different greenhouse gas (GHG) emission scenarios and low/intermediate/high climate sensitivities (Wigley 2003). Only the SRES global temperature projection with intermediate climate sensitivity was used to generate the spatial mean changes. The area average changes of temperature and precipitation of 6 SRES from the baseline climate for Jilin are shown in Table 1.

\subsection{Crop model and its modification}

In selecting a model for the purpose of identifying adaptation options, as well as for assessing impact due to climate change, it would be ideal if the changes in essential signals in the maize growing period (e.g. planting date, maturity period) could be detected at the daily time step and the maize response to cropping practices (such as irrigation and fertilization) could then be quantitatively examined. The site-based crop model, CERES-Maize, embedded in the Decision Support System for Agrotechnology Transfer (DSSAT) version 4.0, developed by Hoogenboom et al. (2004), is operated on a daily time step and takes into account the effects of cultivar, cropping

Table 1. Average changes of temperature and precipitation of 6 Special Report on Emissions Scenarios (SRES) from the

\begin{tabular}{|c|c|c|c|c|c|c|}
\hline & A1B & A1FI & A1T & A2 & B1 & B2 \\
\hline \multicolumn{7}{|c|}{ Temperature $\left({ }^{\circ} \mathrm{C}\right)$} \\
\hline 2020 & 0.58 & 0.62 & 0.79 & 0.57 & 0.63 & 0.74 \\
\hline 2050 & 1.82 & 2.03 & 1.97 & 1.59 & 1.41 & 1.64 \\
\hline 2070 & 2.67 & 3.46 & 2.59 & 2.63 & 1.94 & 2.23 \\
\hline \multicolumn{7}{|c|}{ Precipitation (\%) } \\
\hline 2020 & 2.71 & 2.79 & 3.10 & 2.98 & 2.98 & 3.06 \\
\hline 2050 & 3.84 & 4.54 & 5.07 & 5.30 & 5.42 & 5.60 \\
\hline 2070 & 6.13 & 6.85 & 7.20 & 7.52 & 7.61 & 7.76 \\
\hline
\end{tabular}
baseline climate for Jilin Province 
management, weather, soil moisture, and nutrition on maize in its simulation (Jones et al. 2003). In addition, the cultivar is modeled with explicit genetic coefficients. Thus, the CERES-Maize model has the capacity to provide critical information for identifying potential adaptation options. The model has been widely validated across different climate and soil conditions for different varieties (Wu et al. 1989, Maytín et al. 1995, O'Neal et al. 2002, Gungula et al. 2003, Soler et al. 2007, Braga et al. 2008). In Jilin, Jin et al. $(1996,2002)$ used it in the projection of maize yields at specific locations based on the double $\mathrm{CO}_{2}$ climate scenarios derived from 3 GCMs, and suggested several adaptation options. The CERES-Maize model was also employed by Xiong et al. $(2005,2007)$ to predict the future maize production in China under 2 emission scenarios with daily outputs of the PRECIS regional climate model at $50 \times 50 \mathrm{~km}$ resolution. Here we used the CERES-Maize model to simulate maize growth, development, and yield in Jilin.

\subsubsection{Generating daily weather}

For the purpose of spatial impact analysis, the CERES-Maize model was further developed with spatial simulation capability. The stochastic weather generator SIMMETEO, embedded in DSSAT, was used to produce daily weather for each grid cell from the monthly climate data, including maximum and minimum temperature, precipitation, wet days, and solar radiation. The baseline climate data of 1961 to 1990 was obtained from the Climate Research Unit (CRU, University of East Anglia) global climatology dataset (New et al. 2002) through linear interpolation of the spatial resolution from $10^{\prime} \times 10^{\prime}$ to $5^{\prime} \times 5^{\prime}$ grids. The solar radiation was estimated from the CRU sunlight hours following the method of Tong et al. (2005), and the maximum/minimum temperature was calculated from the mean temperature and its diurnal range (New et al. 2002).

The stochastic weather series generated by SIMMETEO is associated with a random seed. Simulations with the same monthly climate data but different random seeds could show very different yields. An experiment using 1000 random seeds indicated that the mean of the cumulative simulated yield became less variable as more runs were being taken into the sample. Four tests with different groups of random seeds (the first 120 results of the 1000 runs are given in Fig. 2) suggested that the mean value of the cumulative simulations converged after 100 random seed runs. Therefore, the average of 100 cumulative runs with different random seeds was used in this study.

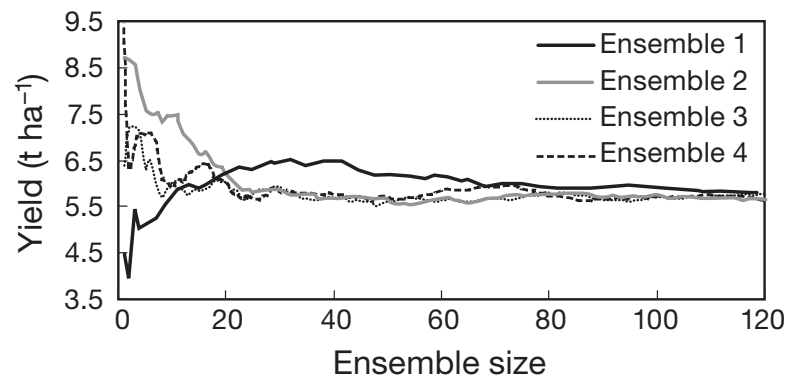

Fig. 2. Cumulative mean simulated yield of 1000 runs at a site with 4 groups of 1000 random seeds. Only the first 120 runs are shown

\subsubsection{Soil data}

The spatial soil information was derived from the ISRIC-WISE (Batjes 2006) database $\left(5^{\prime} \times 5^{\prime}\right)$, which provided most of the soil parameters required by DSSAT within a $100 \mathrm{~cm}$ deep soil profile. Other parameters which are not in the WISE database were estimated accordingly, including: (1) soil albedo (SLAB), determined by the surface soil color (Gijsman et al. 2007); (2) first stage evaporation coefficient (U), drainage coefficient (SWCON), runoff curve number $(\mathrm{CN})$, and root hospitality or clumping factor (WR), calculated by the methods suggested by Iglesias (2006); (3) saturated moisture content (SAT) and lower and upper limits of soil moisture content (LL and DUL), estimated by soil texture in each layer (Saxton et al. 1986, Gijsman et al. 2002); and (4) saturated hydraulic conductivity (SWCN), estimated from soil texture and organic matter using the software SPAW (Saxton \& Rawls 2006).

\subsubsection{Cropping management}

There are 3 main cropping practices included in DSSAT: planting density, nitrogen fertilizer application, and irrigation strategy.

The planting density was set to the same value $(6$ plants $\mathrm{m}^{-2}$ ) for the whole area. The total fertilizer application was obtained from the county statistical data, and only the ammonium nitrogen fertilizer was considered in the fertilization. The total nitrogen application $\left(\mathrm{kg} \mathrm{ha}^{-1}\right)$ in each county was the average annual chemical fertilization consumption derived from the county agriculture census (Jilin Statistical Yearbooks 19902002, Jilin Province Bureau of Statistics, Jilin University Press, Changchun), and applied evenly during the growing season.

The planting management was changed slightly in our study. In the original CERES-Maize model, maize is automatically sown if both soil temperature and soil moisture exceed a given threshold. This rule is not ap- 
propriate for large areas of Jilin, where the required soil water condition could not be fulfilled in the normal dry spring despite the appropriate soil temperature. We therefore revised the planting date to be decided principally by the soil temperature conditions: once the average soil temperature was $>7^{\circ} \mathrm{C}$ on 5 successive days, which is the lower limit of soil temperature for maize emergence (Song et al. 2006), irrigation was applied on the planting day if the soil water content was below the threshold of $20 \%$ of saturated volumetric water content, and then the seed was sown.

The irrigation practice was re-organized as well, in order to examine the effect of total irrigation and application frequency on maize growth and production. Irrigation in DSSAT is originally applied in 2 ways: (1) automatic irrigation that provides the optimal amount of water to cover the estimated soil water deficiency, and (2) scheduled irrigation based on the presetting of application date and amount. In practice, the automatic irrigation method requires an irrigation amount exceeding the official quota of $350 \mathrm{~mm}$, the maximum irrigation amount allowed for maize production by the local government (C. T. Gao pers. comm.) for most areas of Jilin. The scheduled method is not applicable for the spatial simulation, because it does not take into account the actual climate and soil conditions.

Therefore, we designed a 2-step process for each grid to assign the irrigation date and the applied water amount at each irrigation. In the first step, the automatic irrigation feature in DSSAT was employed to preliminarily estimate 4 irrigation parameters under the optimal irrigation regime: (1) the optimal total irrigation requirement $(Q 1),(2)$ the irrigation demand (Irr1) at 4 growth stages (i.e. before emergence, juvenile, tasseling and flowering, and grain filling), (3) the irrigating frequency $(F 1)$ for each stage, and (4) the ratio of water demand $(P 1)$ for each stage, which was calculated by Eq. (3) (in which the subscript ' $i$ ' refers to the $i$ th growth stage). The second step was to refine these parameters according to the local irrigation quota (Q2). The irrigation amount in each stage (Irr2) was estimated by the corresponding $P 1$ and $Q 2$ following Eq. (4). The maximum amount at each irrigation for a certain growth stage, IrrMax2, was obtained by $F 1$ and Irr2 as shown in Eq. (5). The real irrigation is applied when the available water in top soil is $<60 \%$ of saturated volumetric water content. The actual applied amount for each irrigation (IrrAmt2) is the minimum value of the soil water deficit (SWDEF) estimated in DSSAT and the IrrMax2 (see Eq. 6). The 2-step method has the advantage of allowing the irrigation water to be properly allocated, depending on the specific growth condition.

$$
\begin{aligned}
& P 1_{i}=\operatorname{Irr} 1_{i} / Q 1 \\
& \operatorname{Irr} 2_{i}=P 1_{i} \cdot Q 2 \\
& \operatorname{IrrMax} 2_{i}=\operatorname{Irr} 2_{i} / F 1_{i} \\
& \operatorname{IrrAmt2} 2_{i}=\min \left(\operatorname{IrrMax} 2_{i}, \text { SWDEF }\right)
\end{aligned}
$$

In this study, irrigation application efficiency (EffIrr), which is the ratio of the volumetric water available for the crop to the irrigation quota, was 0.4 for the furrow irrigation system, as suggested by Su \& Liu (2006). This means that the actual maximum water available for the crop, referred to as 'effective irrigation', is $140 \mathrm{~mm}$ in the furrow system of Jilin under the official $350 \mathrm{~mm}$ irrigation quota. The effective irrigation amount (EffIrrAmt) at each irrigation for the ith growth stage is calculated using Eq. (7).

$$
\text { EffIrrAmt }_{i}=\operatorname{IrrAmt}_{i} \cdot \text { EffIrr }
$$

\subsection{Genetic coefficient selection}

\begin{tabular}{|c|c|c|c|c|}
\hline \multicolumn{2}{|r|}{ Genotype coefficient } & \multirow{3}{*}{$\begin{array}{l}\text { Initial reference range } \\
125-400\end{array}$} & \multicolumn{2}{|c|}{ Cultivar } \\
\hline & & & Late & Early \\
\hline P1 & $\begin{array}{l}\text { Thermal time from seedling emergence to the end of the juvenile stage } \\
\text { (degree days above the base temperature of } 8^{\circ} \mathrm{C} \text { in the juvenile stage) }\end{array}$ & & 280 & 270 \\
\hline P2 & $\begin{array}{l}\text { Photoperiod sensitivity associated with delayed growth under the } \\
\text { unfavorable long-daylight condition (no unit) }\end{array}$ & $0.1-0.8$ & 0.3 & 0.3 \\
\hline P5 & $\begin{array}{l}\text { Thermal time from silking to physiological maturity (degree days above } \\
\text { base temperature of } 8^{\circ} \mathrm{C} \text { in the mature stage) }\end{array}$ & $500-900$ & 790 & 700 \\
\hline G2 & Potential maximum number of kernels per plant & $500-850$ & 720 & 720 \\
\hline G3 & Kernel filling rate under optimum conditions $\left(\mathrm{mg} \mathrm{d}^{-1}\right)$ & $5-12$ & 8.5 & 8.5 \\
\hline PHINT & $\begin{array}{l}\text { Interval in thermal time between successive leaf tip appearances (degree } \\
\text { days above base temperature of } 8^{\circ} \mathrm{C} \text { ) }\end{array}$ & $35-75$ & 38.9 & 38.9 \\
\hline
\end{tabular}

To describe a crop, the CERES-Maize model in DSSAT requires 6 genetic coefficients which are essential factors for crop growth and yield formation (Table 2). Four

Table 2. Maize genetic coefficients and cultivars 
of them (P1, P2, P5, and PHINT) control the timing of phenological stages, and the other 2 (G2 and G3) characterize the potential yield under optimal conditions. In most previous studies applying the CERES-Maize model in China, the genetic coefficients were estimated from the observed site data (Yang et al. 2006, Yu et al. 2006). Some studies expanded the spatial scale to provincial (Wu et al. 1989) and country-wide (Cui 2005, Xiong et al. 2007), relying on the site-observed cultivar as representative for a large region, such as in the study of Cui (2005), which universalized the genetic coefficients estimated by the observed data at Dunhua to all of Jilin Province. Xiong et al. (2007) examined the accuracy of 1 representative cultivar in Jilin by comparing the simulation derived by the nearest weather station to the county census in $50 \times 50 \mathrm{~km}$ grids, and pointed out a significant uneven overestimation of the mean annual yield. Such biases in spatial simulations may be caused by the homogeneous application of the cultivar obtained from a site to a region, where the actual maize cultivars in the eastern area (including Panshi, Baishan, and Tonghua) were quite different from those in the western and central areas (including Tongyu, Changling, Shuangliao, Changchun, and Siping), corresponding to the different solar radiation and thermal potentials (Luo et al. 2000).

There is a mismatch when using data from a single agricultural experimental station to generate spatial distribution of genetic coefficients for a process-based crop model like CERES-Maize at the regional scale. Thus extensive observed stations that cover the spatial area of interest are needed, but such a requirement is seldom satisfied for most crop production research. An alternative approach is to classify the area into different zones based on pre-defined factors related to crop production, such as identification of crop zones based on specific agro-ecological characteristics, i.e. the agro-ecological zones (AEZ) method (Xiong et al. 2008), and for each classified zone, single and/or multi-observed station data can be used to generate its genetic coefficients. As the present study focused on the impact of climate change, it appears to be much more appropriate to classify the zoning of maize cultivars based on climate characteristics. However, there are not enough available observation stations in Jilin to support a selection of maize cultivars for each conventional climate zone (Luo et al. 2000). Consequently, only 2 distinctive maize cultivar zones were found through calibration, and based on these zones, cultivars were selected and the maize model was calibrated, as described below.
Considering the spatial heterogeneity of maize cultivars, the genetic coefficients used in this study were calibrated and validated by multi-year observations at 11 agro-meteorological stations located in different regions of Jilin (Table 3). The required data, including daily weather records (maximum/minimum air temperature, precipitation, sunlight duration, and relative humidity) and the observed crop data from 1996 to 2006 (annual yield, planting date, harvest date), were obtained from the China Meteorological Data Sharing Service System (http://cdc.cma.gov.cn/index.jsp).

The evaluating indicator $\left(I_{e}\right)$ was a combination of 2 indices, which were used for the genetic coefficients selection. The maturity date index $\left(I_{m}\right)$ was defined as the difference in physiological stage between simulation and observation, and the yield index $\left(I_{Y}\right)$ was used to evaluate the fitness of the simulated yield $Y_{\text {sim }}$ :

$$
\begin{aligned}
I_{e} & =I_{m}+I_{y} \\
& =\left(1-M_{\text {sim }} / M_{\text {obs }}\right)^{2}+\left(1-Y_{\text {sim }} / Y_{\text {obs }}\right)^{2}
\end{aligned}
$$

where $M_{\text {sim }}$ and $M_{\text {obs }}$ are the simulated and observed maturity dates, respectively. Thus, the smaller $I_{Y}\left(I_{m}\right)$ indicated the better estimate of yield (maturity date) for a certain cultivar.

An iteration method was applied to obtain the optimal cultivar (see Fig. A1 in Appendix 1). Firstly, 30 trial groups of genetic coefficients were sampled within the reference range using the uniform design method (Zhang et al. 2004) at each iterative step. The initial reference ranges of P1, P2, P5, G2, and G3 are from DSSAT documents (Table 2). Secondly, a new narrower range for sampling trial coefficients was decided from the cultivars with the 2 smallest $I_{e}$ from the 30 trials, and the iteration was completed when the difference between the upper and lower range of genetic coefficients was $<5 \%$ of its magnitude.

Table 3. Calibration at 11 agro-meteorological stations (see Fig. 1 for county locations). $Y_{\text {sim }}: Y_{\text {obs }}$ and $M_{\text {sim }}: M_{\text {obs }}-11$ yr mean ratios of simulations to observations for yield $(Y)$ and maturity date $(M)$

\begin{tabular}{|lcccccc|}
\hline County & ${ }^{\circ} \mathrm{N}$ & ${ }^{\circ} \mathrm{E}$ & Altitude $(\mathrm{m})$ & Cultivar & $Y_{\text {sim }}: Y_{\text {obs }}$ & $M_{\text {sim }}: M_{\text {obs }}$ \\
\hline Changling & 123.97 & 44.25 & 190.40 & Late & 0.55 & 0.94 \\
Nongan & 125.16 & 44.41 & 190.00 & Late & 0.92 & 1.03 \\
Yushu & 126.53 & 44.83 & 206.00 & Late & 0.87 & 1.06 \\
Lishu & 124.30 & 43.35 & 160.00 & Late & 1.05 & 1.05 \\
Jian & 126.15 & 41.10 & 177.70 & Late & 0.94 & 0.96 \\
Shulan & 126.93 & 44.42 & 252.00 & Early & 0.87 & 1.06 \\
Yongji & 126.56 & 43.70 & 232.40 & Early & 0.99 & 0.95 \\
Dunhua & 128.20 & 43.37 & 523.70 & Early & 1.23 & 1.13 \\
Liaoyuan & 125.08 & 42.92 & 254.00 & Early & 1.05 & 1.01 \\
Meihekou & 125.63 & 42.53 & 341.50 & Early & 0.94 & 0.94 \\
Huadian & 126.75 & 42.98 & 264.20 & Early & 0.90 & 1.00 \\
\hline
\end{tabular}


Taking account of the average $I_{e}$ at 11 stations in $11 \mathrm{yr}$ (from 1996 to 2006), we found that the range of physiological coefficients (P1, P2, P5) at the stations located in the west and middle areas showed a different trend from those in the southeast. Therefore, 2 groups of genetic coefficients (Table 2 ) were estimated for the 2 different areas, with 5 sites for the late cultivar and 6 sites for the slightly early cultivar (Table 3 ). The bias of the simulated yield (growing seasons) at most stations was in the $\pm 10 \%$ range of its observed value (Table 3 )

The boundary between the late and early cultivar (shown by the bold line in Fig. 1) was determined based on the following criteria: (1) calibration at 11 agro-meteorological sites; (2) maize cultivar distribution in northeast China estimated from the local climate temperature conditions (Luo et al. 2000); and (3) conformability of the annual yield simulation to its statistic with respect to the 2 cultivars in each county. The cultivar selection based on the 11 sites that had reliable observed daily weather data and crop records was the top criterion among the 3 in determining the boundary, followed by local observations, and finally the comparison of the yield simulations obtained by gridded climate data with county censuses of yield.

To validate the model for spatial simulation, we compared the census yields and the simulations at the county level. The annual yield was simulated with the CRU time-series climate data from 1990 to 2002 (Mitchell \& Jones 2005), the 2 cultivars obtained, as well as the soil properties and crop management mentioned above. The county-level yield was obtained by aggregating the yield simulation for grids where maize was sown. The percentage of maize-sown area in a $5^{\prime} \times$ 5' grid was obtained from the Global 18 Major Crops dataset in 1992 (Leff et al. 2004). The annual county maize yield data were obtained from the 1990-2002 statistical yearbooks of Jilin Province (Jilin Province Bureau of Statistics, Jilin University Press, Changchun).

Comparison was made of the mean and standard deviation (SD) of the $12 \mathrm{yr}$ simulations to that of the county census yields (Fig. 3). The mean yield simula- tions were about $10 \%$ lower on average than the reported county statistics. The relative bias in the central part, ranging from -18 to $11 \%$, was moderate, which indicated that the model performed a reasonable estimation of mean yield in the major maize-sown area. However, there was a significant overestimation in low-yield counties (e.g. Tongyu in the western dryland area, and counties close to the eastern mountains) and a slight underestimation in the high-yield area (Fig. 3a), i.e. the Siping region. The spatial correlation coefficient of the aggregated simulations with the 47 county censuses reached 0.6 (>99\% confidence level, 2 -tailed $t$-test). With regard to the SD of the 12 yr yield, the simulated values were much smaller than those of the census for most counties, except those where mean yields were overestimated (Fig. 3b).

\section{RESULTS}

\subsection{Projected regional climate changes}

This study was mainly focused on the impact of changes in monthly mean temperature and total precipitation, with other climate variables, such as solar radiation and wind speed, being kept at the baseline level. The median value of climate change projections showed a consistent warming trend and increased precipitation during the maize growing season (April to September, Fig. 4). The temperature increased by around $0.6,1.6$, and $2.4^{\circ} \mathrm{C}$ in the years 2020, 2050, and 2070, respectively, with slight spatial variations, and the total precipitation increased by around 2.3, 6.2, and $9.0 \%$, correspondingly. The warming trends in April, August, and September were moderately higher than in the other 3 months (May, June, July), whereas 85\% of the precipitation increase happened in May, August, and September (data not shown).

Although both temperature and precipitation increased, the change of the dry/wet status was more pertinent to crop yield. We measured the change in dry/wet status in the growing season by looking at the

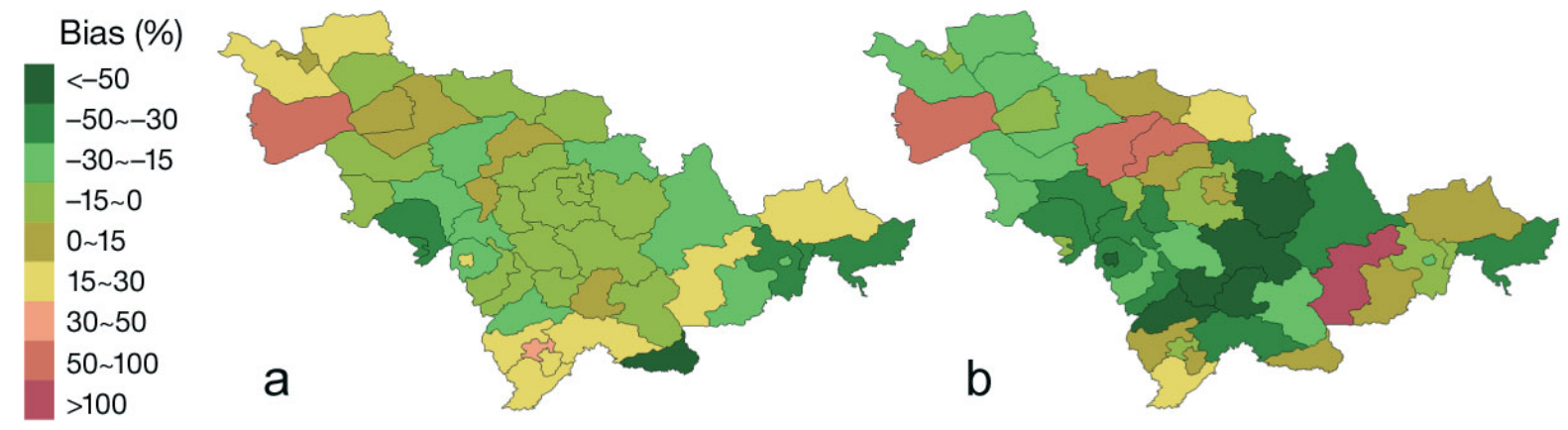

Fig. 3. Bias of (a) simulated and county-census mean yields and (b) their standard deviations 


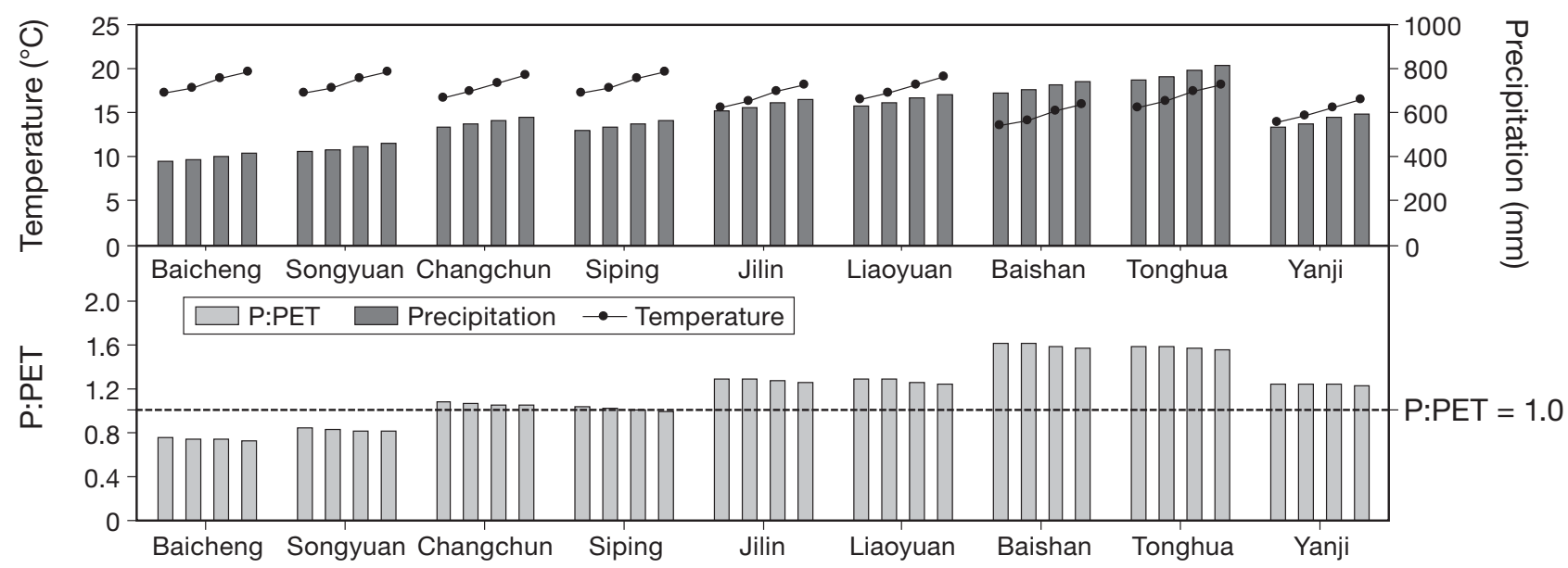

Fig. 4. Baseline climate and the median climate change scenarios in Jilin Province in 2020, 2050, and 2070 (values from left to right in graphs) during the maize growing season (April to September) for mean monthly temperature, total precipitation, and the ratio of total precipitation to potential evapotranpiration (P:PET)

ratio of precipitation to potential evapotranspiration (P:PET). The monthly PET was calculated using the monthly average temperature by the Thornthwaite method (Ma et al. 2005). There was a clear correlation between maize yield and P:PET for the central and western areas (Baicheng, Songyuan, Changchun, and Siping; see Fig. A2 in Appendix 1).

For all regions in Jilin Province, the P:PET ratio was projected to decrease in the future. In the central area, the total PET from April to September surpassed precipitation (data not shown), which implies an enhanced aridification trend for all regions of Jilin. The current semi-dry area in the central region is likely to become even drier, and the present dry west may undergo a larger water deficit in the coming decades.

\subsection{Impacts on yield}

\subsubsection{Spatial pattern of impacts for the median projection}

In general, the future yield was projected to decrease in the main sown area, but increase in a few counties in the eastern area. The wide western and central regions, including Baicheng, Songyuan, Changchun, Siping, and parts of Liaoyuan and the Jilin District, were likely to experience a significant yield reduction due to the increasing dryness. The largest reduction tended to be about 1.1, 2.1, and $2.7 \mathrm{tha}^{-1}$ in the years 2020, 2050, and 2070, respectively, for the central cropping area, which covers Changchun, most of Songyuan, and the northern part of Siping (Fig. 5).

In contrast, a favorable rise in yield emerged for the current marginal maize-growing regions in the eastern mountainous areas. Some unsuitable areas at present could have a doubled maize yield in 2050. It is worth noting that in the southeast of Tonghua and part of Yanji, the future change in yield was initially projected to go up in 2020 but to fall again by around $2.0 \mathrm{t} \mathrm{ha}^{-1}$ towards the end of this century.

Projected yield changes were significantly different from one region to another (Fig. 5).

In regions showing a downward trend, the reduction of regional average yield in central counties (Songyuan, Changchun, Liaoyuan, and Siping) was projected to be about $10 \%$ in 2020 but more than 20 and $30 \%$ in 2050 and 2070, respectively (Table 4). For the Jilin District and Tonghua, the reduction was less obvious initially but became significant towards the middle and end of the century. The 2 eastern regions, Yanji and Baishan, showed a large benefit in maize production during the first $50 \mathrm{yr}$. However, the gains might be retarded towards the end of the century because the potential productivity of the existing cultivar would have been fully exploited in line with the corresponding local temperature increases.

\subsubsection{Uncertainty analysis of yield projections}

Fig. 6 displays the predictions under each scenario in order to identify the uncertainty within specific SRES. In the yield reduction areas, the biggest reduction was projected by the A1T scenario in 2020, but was overtaken by the A1FI scenario in 2070. The projection of the B1 scenario demonstrated the smallest reduction for most of the area in most future periods. With regard to the positive change areas of Baishan and Yanji, the differences among 6 SRES projections are much less than those in the areas with reduced yield. The lowest yield was projected by the B1 group simulations for 


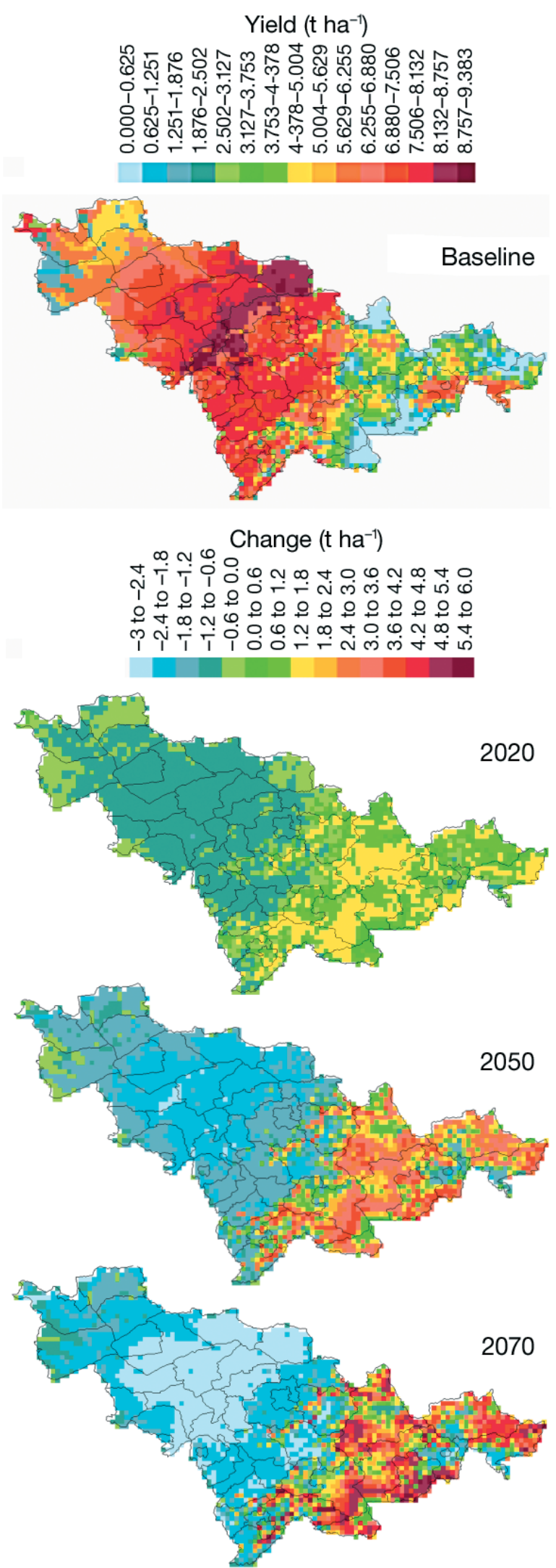

Fig. 5. Simulated maize yield ( $\mathrm{t} \mathrm{ha} \mathrm{h}^{-1}$ ) at baseline and yield change in 2020, 2050, and 2070.
Baishan in 2050, but was again overtaken by the A1FI group simulations in 2070. For Yanji, the A1FI group simulation consistently projected the lowest forecasting for all time periods.

We explored the probabilities of 6 reduction levels $(5,10,20,30,40$, and $50 \%$ reduction relative to the baseline yield) to quantify the likelihood of yield change. The probability density distribution of 120 regional yield simulations (from $20 \mathrm{GCMs}$ under 6 SRES) was estimated by the Gauss kernel method (Parzen 1962), and the cumulative probability of each reduction level was then calculated (Fig. 7). Baicheng was most vulnerable to climate change. For the same reduction rates, this region demonstrated the highest probabilities for all future time periods simulated. In contrast, Jilin District showed the most resilience. Its 2020 reduction was projected to be less than $10 \%$ by all simulations, with a relative small probability that it would have a $50 \%$ reduction by 2070 . Apart from the Jilin District, other maize-growing regions all showed more than $90 \%$ probability to have a $10 \%$ reduction for 2050 , and $20 \%$ reduction for 2070 .

\subsection{Effects on phenology}

Climate change also has an impact on maize phenology, since temperature changes influence the schedule of maize sowing, flowering, and grainfilling.

\subsubsection{Sowing date}

Spatially, the sowing date of maize will slightly advance in the future due to the warming trend in spring. The average result of 100 runs under the median projection of climate change (see Section 2.2.) revealed that the sowing date was $1.5,3$, and 4 d earlier in 2020, 2050, and 2070, respectively, than the baseline for the main cropping areas, and the advance in the eastern regions even exceeded $1 \mathrm{wk}$ after 2050 but with high spatial variability (Fig. A3 in Appendix 1). The advances in the eastern regions were due to the comparatively lower sowing temperature threshold of April and May that could be easily surpassed during future warming. Phenologically, the early sowing helps to prolong the maturity season of the current early maize cultivar in the east and is a favorable change for maize yield.

\subsubsection{Flowering date}

Similar to the sowing date changes, there was also an advance in flowering date but with a more homoge- 
Table 4. Maize yield projections ( $\mathrm{tha}^{-1}$ ) in 2020, 2050, and 2070 using 20 general circulation models (GCMs) under 6 scenarios from the Special Report on Emissions Scenarios (SRES). Median: median yield of 120 projections by 20 GCMs under 6 scenarios; Range: 10th and 90th percentile range of 120 projections; Change: reduction ratios to baseline yield

\begin{tabular}{|c|c|c|c|c|c|c|c|c|c|c|}
\hline \multirow{2}{*}{ Region } & \multirow{2}{*}{ Baseline } & \multicolumn{3}{|c|}{$-2020 \longrightarrow$} & \multirow{2}{*}{\multicolumn{3}{|c|}{$\overline{\text { Median }} 2050-\overline{ }$}} & \multirow[b]{2}{*}{ Median } & \multirow{2}{*}{$\begin{array}{c}2070- \\
\text { Range }\end{array}$} & \multirow[b]{2}{*}{ Change (\%) } \\
\hline & & Median & Range & Change (\%) & & & & & & \\
\hline Baicheng & 5.08 & 4.34 & $3.80-4.55$ & -14.6 & 3.66 & $2.60-4.17$ & -27.9 & 3.26 & $1.85-3.92$ & -35.9 \\
\hline Songyuan & 6.94 & 6.33 & $5.67-6.64$ & -8.7 & 5.27 & $3.92-5.85$ & -23.9 & 4.66 & $3.00-5.45$ & -32.8 \\
\hline Changchun & 8.15 & 7.33 & $6.77-7.68$ & -10.0 & 6.02 & $5.00-6.72$ & -26.2 & 5.33 & $4.03-6.22$ & -34.6 \\
\hline Siping & 7.14 & 6.35 & $5.76-6.64$ & -11.0 & 5.26 & $4.07-5.86$ & -26.4 & 4.64 & $3.21-5.38$ & -35.0 \\
\hline Liaoyuan & 7.14 & 6.46 & $6.04-6.71$ & -9.5 & 5.43 & $4.66-5.93$ & -23.9 & 4.88 & $3.89-5.48$ & -31.6 \\
\hline Jilin District & 6.98 & 6.76 & $6.50-6.90$ & -3.2 & 5.96 & $5.12-6.50$ & -14.6 & 5.33 & $4.09-6.13$ & -23.6 \\
\hline Baishan & 4.23 & 4.75 & $4.51-5.03$ & 12.2 & 5.60 & $5.27-5.86$ & 32.3 & 5.71 & $4.85-5.97$ & 34.8 \\
\hline Tonghua & 7.06 & 7.04 & $6.86-7.13$ & -0.3 & 6.39 & $5.49-6.79$ & -9.6 & 5.73 & $4.41-6.45$ & -18.9 \\
\hline Yanji & 4.16 & 4.62 & $4.45-4.82$ & 11.1 & 5.18 & $4.79-5.34$ & 24.6 & 5.15 & $4.05-5.43$ & 23.9 \\
\hline
\end{tabular}

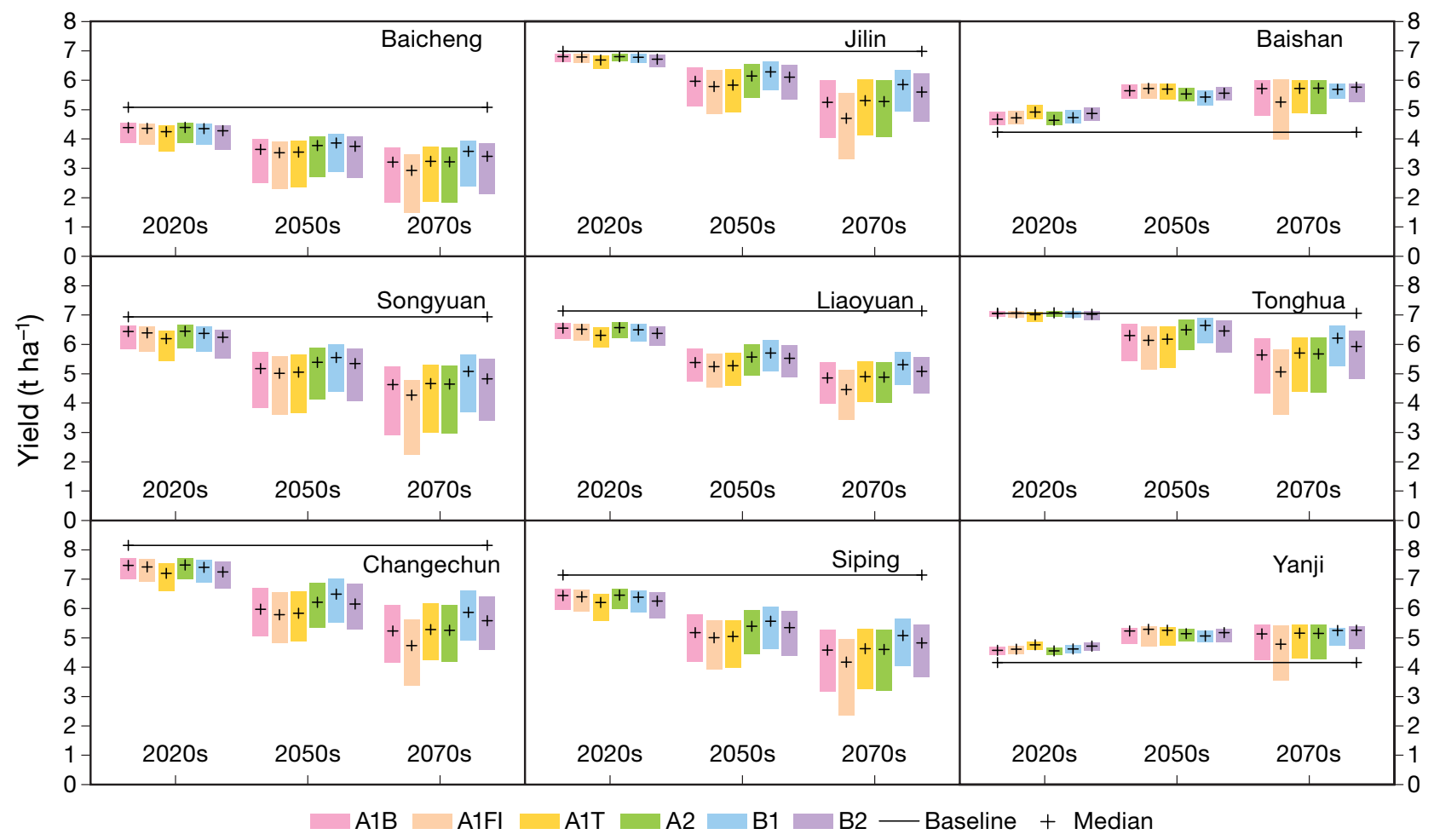

Fig. 6. Projected range of maize yield of 9 regions under 6 Special Report on Emissions Scenarios (SRES: A1B, A1FI, A1T, A2, B1, B2). The black crosses are the median yields of 20 projections, and the colored bars show the 10th to 90th percentile ranges. The baseline yield is shown as the black line

neous pattern for the whole province. The flowering dates were 2, 3, and 4 d earlier for 2020, 2050, and 2070 (Fig. A4 in Appendix 1).

\subsubsection{Maturity days}

Distinctive from the changes in sowing and flowering phases, the entire number of maturity days (from sowing to harvest) was predicted to shrink in the central and western plains, ranging from about 10 to $30 \mathrm{~d}$ shorter in the next few decades, but lengthened by 8 to $22 \mathrm{~d}$ in the eastern mountainous areas covering Yanji, Baishan, and part of Tonghua (Fig. A5 in Appendix 1).

\subsubsection{Grain-filling period}

Despite the advance in both sowing and flowering dates ( 1 to $5 \mathrm{~d}$ earlier), the changes in the reproduction phase (periods after flowering, including tasseling and grain-filling) may contribute to most of the changes in maize phenology (10 to $30 \mathrm{~d}$ shorter in middle-western 


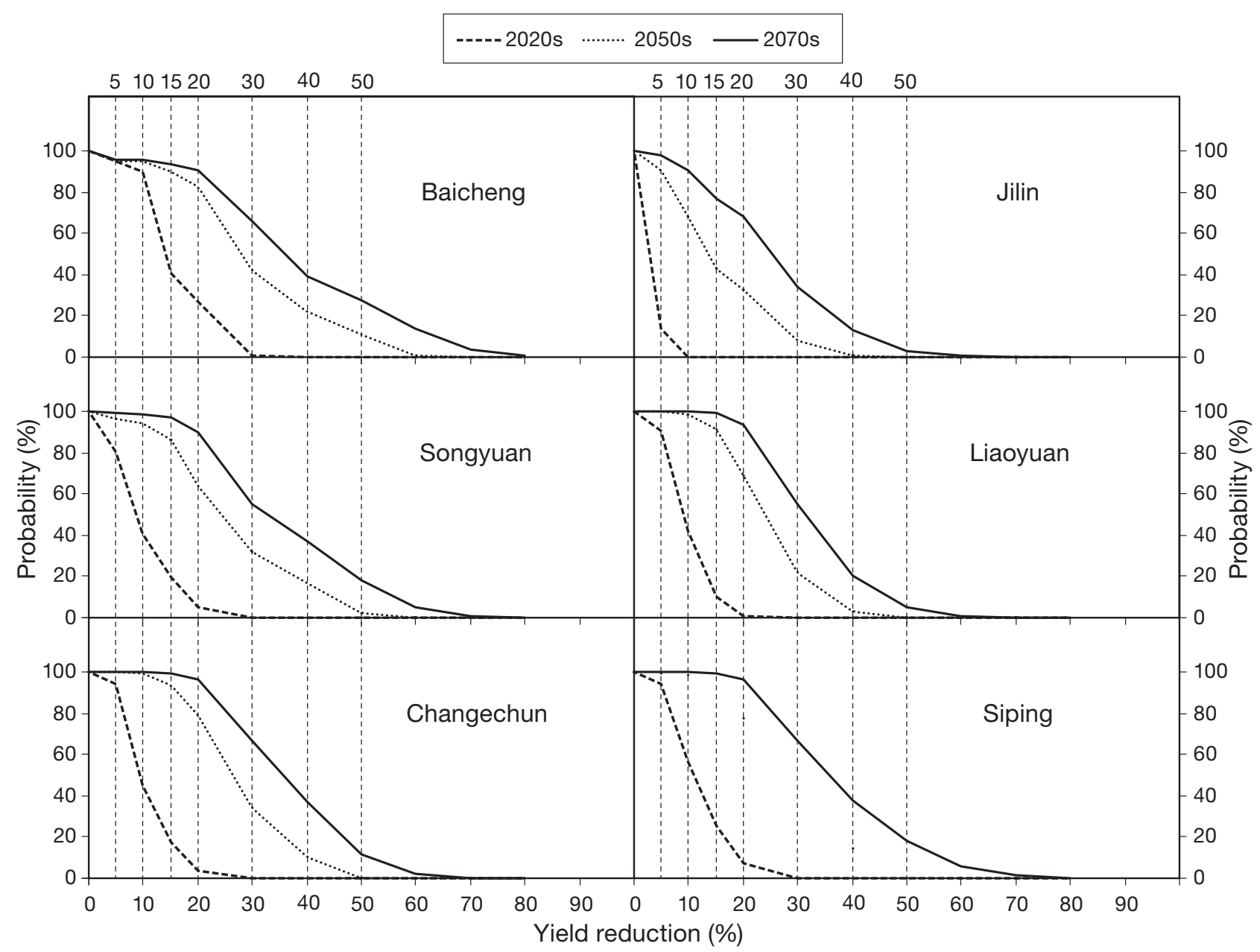

Fig. 7. Probability of maize yield reduction of 6 regions in 2020, 2050, and 2070

areas and 8 to $22 \mathrm{~d}$ longer in the east). Hence, it is likely that the varied length of the reproduction phase may be linked to yield changes. In this part of the study, the single run simulation of both yield and growth phases at selected sites was calculated and analyzed.

Four sites were chosen for this experiment, 2 in the far west (Baicheng and Tongyu), and 2 in the east (Dunhua and Huadian). Three periods of the growing phase were considered: the period from sowing to tasseling, from the first tasseling to the beginning of grain-filling, and from grain-filling to maturity.

At Baicheng and Tongyu, the shrinking of the maize filling period represented more than half of the overall reduction of the growth season, while the simulations at Dunhua and Huadian showed the reverse: the grainfilling was prolonged despite the shortening trend in the periods from sowing to flowering (Fig. 8). The possible increase in maize yield in eastern cold counties was mainly attributed to the improvement of local thermal conditions, as regional warming develops, which could significantly extend the grain-filling phase. It is also worth noting that since the maize yield in some western counties is likely to decrease in the future, even in the automatic irrigating test (in which irrigation supplies enough water for maize growth) such a reduction in yield is probably not caused by a deficient water supply, but rather is induced by the shortened grain-filling period.

\section{4. $\mathrm{CO}_{2}$ fertilization effect}

The increasing atmospheric $\mathrm{CO}_{2}$ concentration was hypothesized to have positive influences on $\mathrm{C} 4$ crop growth, due to the fact that it accelerates potential photosynthesis production (Kimball 1983) and increases leaf stomatal resistance, which in turn reduces the evaportranspiration (Hoogenboom et al. 1995). However, such a hypothesis of $\mathrm{CO}_{2}$ fertilization was not supported by some studies based on open-air experiments (Leakey et al. 2006), and even in some 

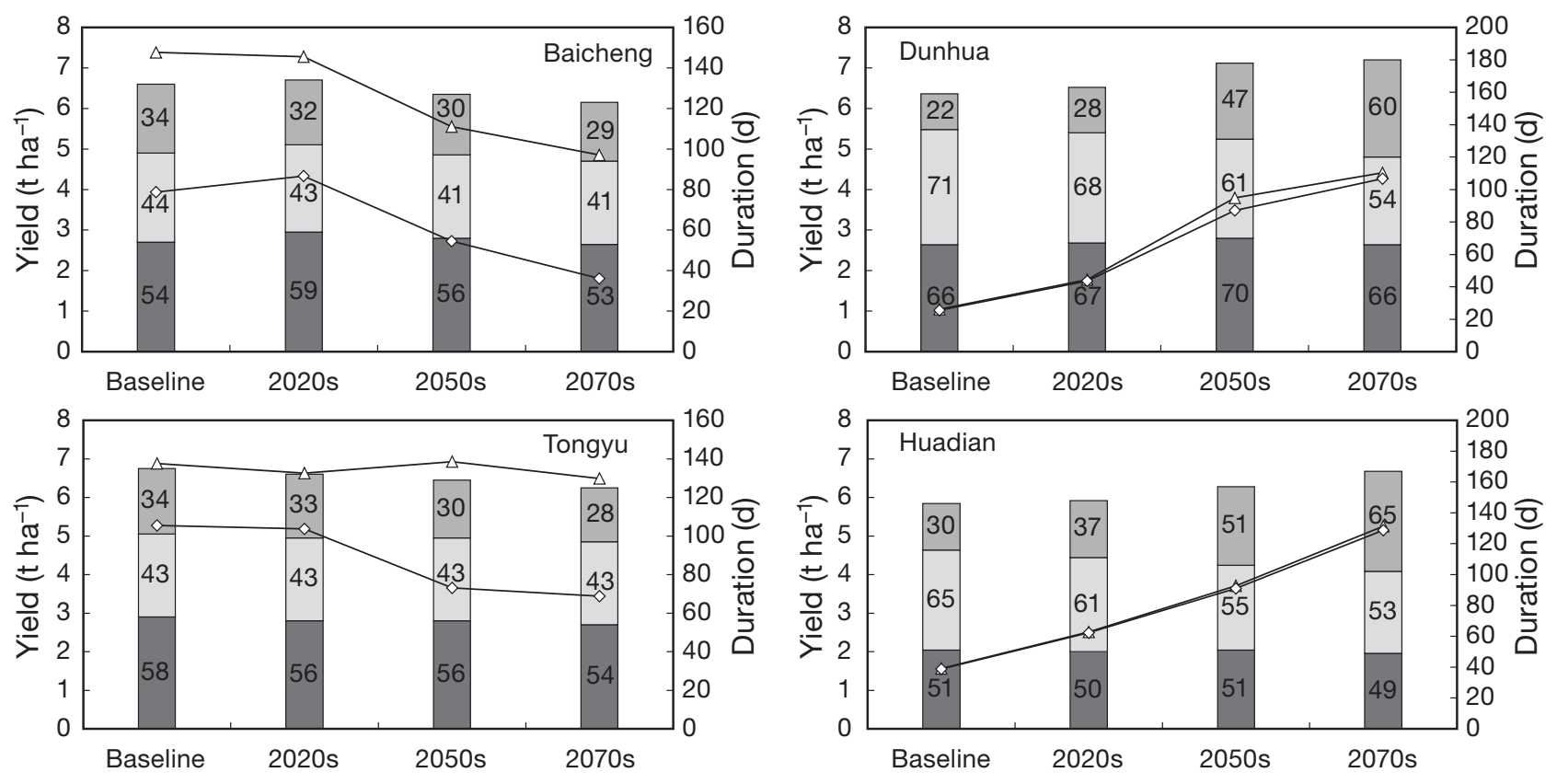

$\square$ Sowing - tasseling begins $\square$ Tasseling begins - filling begins $\square$ Filling begins - filling ends $\rightarrow-$ Auto irr $\diamond-$ Control irr

Fig. 8. Maize yield and phenological indicators under 2 irrigation strategies at 4 selected sites. The line and symbols show the simulated yield obtained using automatic/controlled irrigation

confirmed cases, the observed yield increase was much smaller than expected (Leakey et al. 2009). Nevertheless, in order to obtain a comprehensive view on the impacts of future climate change on food production, we tested $\mathrm{CO}_{2}$ fertilization on the maize yield of Jilin based on CERES-Maize by taking into account both the effects of $\mathrm{CO}_{2}$ on the daily photosynthesis rate and stomatal resistance.

The SRES A1FI and B1 scenarios were selected to measure the $\mathrm{CO}_{2}$ fertilization effect on yield. The $\mathrm{CO}_{2}$ concentration of these 2 scenarios and their corresponding stomatal resistance are given in Table 5.

As shown in Table 6, the CERES-Maize model simulated significant $\mathrm{CO}_{2}$ fertilization effects for both A1FI

Table 5. Relationship of $\mathrm{CO}_{2}$ concentration and the corresponding stomatal resistance as given in DSSAT 4.0

\begin{tabular}{|lcc|}
\hline & $\mathrm{CO}_{2}(\mathrm{ppm})$ & $\begin{array}{c}\text { Stomatal resistance used } \\
\text { in CERES-Maize }\left(\mathrm{s} \mathrm{m}^{-1}\right)\end{array}$ \\
\hline Baseline & & \\
1961-1990 & 330.0 & 65.84 \\
A1FI & & \\
2020 & 417.51 & 76.50 \\
2050 & 569.86 & 99.87 \\
2070 & 723.82 & 126.68 \\
B1 & & 75.71 \\
2020 & 411.61 & 86.47 \\
2050 & 487.24 & 91.92 \\
2070 & 522.03 & \\
\hline
\end{tabular}

and B1 scenarios. On average, the trade-offs of positive effects of elevated $\mathrm{CO}_{2}$ concentration on yield reduction is about 6,14 , and $21 \%$ in 2020, 2050, and 2070, respectively. Relying on regular irrigation, the dry western regions experienced much more favorable effects from the elevated $\mathrm{CO}_{2}$ concentration than the central and eastern regions. Beicheng and Songyuan showed the highest improvement for all future time periods, with half or more of the yield reduction being offset by the enhanced $\mathrm{CO}_{2}$ fertilization. By comparing the results of $\mathrm{A} 1 \mathrm{FI}$ to $\mathrm{B} 1$, it is clear that higher $\mathrm{CO}_{2}$ concentrations in future change projections have a more favorable fertilization effect on yield. Although the favorable effects of $\mathrm{CO}_{2}$ on yield are likely to be significant, it cannot offset the yield reduction, especially toward the end of this century.

\subsection{Potential adaptive strategy}

As discussed previously, the changes in dryness and length of grain-filling are the 2 main reasons why future maize yield may decline in the western and central areas of Jilin Province. Therefore, potential adaptations can be achieved by improving irrigation efficiency and changing the sowing schedule or introducing new cultivars that require longer thermal accumulation in response to the predicted increases in the maize growth season. 
Table 6. Change ratio (\%) of maize yield with/without a $\mathrm{CO}_{2}$ effect under the A1FI and B1 scenarios to the baseline level

\begin{tabular}{|c|c|c|c|c|}
\hline & \multicolumn{2}{|c|}{ A1FI- } & \multicolumn{2}{|c|}{$-\mathrm{B} 1-$} \\
\hline & Without $\mathrm{CO}_{2}$ & With $\mathrm{CO}_{2}$ & Without $\mathrm{CO}_{2}$ & With $\mathrm{CO}_{2}$ \\
\hline \multicolumn{5}{|c|}{ Baicheng } \\
\hline 2020 & -14.2 & -2.0 & -14.3 & -3.0 \\
\hline 2050 & -30.5 & -5.5 & -23.0 & -5.4 \\
\hline 2070 & -42.4 & -7.8 & -29.0 & -8.5 \\
\hline 2020 & -7.8 & 1.7 & -8.1 & 0.8 \\
\hline \multicolumn{5}{|c|}{ Songyuan } \\
\hline 2050 & -27.7 & -7.3 & -19.9 & -7.3 \\
\hline 2070 & -38.5 & -8.6 & -26.7 & -8.6 \\
\hline 2020 & -8.9 & -2.4 & -9.3 & -3.1 \\
\hline \multicolumn{5}{|c|}{ Changchun } \\
\hline 2050 & -28.9 & -15.3 & -20.4 & -10.4 \\
\hline 2070 & -41.8 & -21.2 & -27.9 & -16.6 \\
\hline 2020 & -10.4 & -2.9 & -10.5 & -3.1 \\
\hline \multicolumn{5}{|c|}{ Siping } \\
\hline 2050 & -29.8 & -12.6 & -22.0 & -10.2 \\
\hline 2070 & -41.5 & -15.6 & -28.8 & -14.8 \\
\hline 2020 & -8.8 & -6.0 & -9.0 & -6.2 \\
\hline \multicolumn{5}{|c|}{ Liaoyuan } \\
\hline 2050 & -26.6 & -19.7 & -20.0 & -15.3 \\
\hline 2070 & -37.0 & -26.6 & -25.7 & -20.1 \\
\hline 2020 & -2.8 & 0.9 & -2.9 & 0.8 \\
\hline \multicolumn{5}{|c|}{ Jilin District } \\
\hline 2050 & -17.0 & -8.1 & -10.0 & -3.83 \\
\hline 2070 & -32.6 & -18.9 & -16.1 & -8.96 \\
\hline 2020 & 0.02 & 2.56 & -0.02 & 2.4 \\
\hline \multicolumn{5}{|c|}{ Tonghua } \\
\hline 2050 & -13.0 & -6.1 & -5.9 & -1.3 \\
\hline 2070 & -28.2 & -16.9 & -12.1 & -6.4 \\
\hline
\end{tabular}

\subsubsection{Improving irrigation efficiency}

The sensitivity of the maize yield to increasing water supply was tested at Baicheng and Tongyu, both in the western areas. We conducted a series of experiments of increasing the total effective irrigation from 140 to $300 \mathrm{~mm}$ with an increment of $20 \mathrm{~mm}$. It is evident that the increase in effective irrigation helped to maintain the present maize yield in the future with climate change for western regions (Fig. 9). For Baicheng, the effective irrigation was required to increase approximately $30 \%$ in 2020 , and to be nearly doubled in 2050 , in order to acquire the baseline level yield. However, in 2070, even an amount of 300 mm effective irrigation could not maintain the baseline level yield. The situation appeared to be worse in Tongyu, where the yield loss could not be compensated for by increasing irrigation after 2050, since the grain-filling period of the current cultivar is shortened under a warming climate. The positive effect was more significant when the effective irrigation increased from 140 to $220 \mathrm{~mm}$, but less so for higher levels of irrigation.

When using the current furrow irrigation methodwith its low efficiency of only 0.4 , which is much lower than the value of $0.7-0.8$ in developed countries (Xu \& Kang 2002) - the maximum effective irrigation (140 $\mathrm{mm}$ ) under the local official quota $(350 \mathrm{~mm}$ ) cannot satisfy the water demand to keep the baseline maize yield of Jilin in future decades. If irrigation efficiency can be increased to 0.55 in the year 2020, which is the objective value in the national water resources plan (Ministry of Water Resources 2010, see www.mwr.gov.cn/ slzx/slyw/201011/t20101125_246091.html), the maximum effective irrigation will increase to $192.5 \mathrm{~mm}$, and the the maize yield can then be maintained in 2020. In 2050, the water required to keep yields at the baseline level can only be achieved at Baicheng if irrigation efficiency is improved to 0.8 by applying a sprinkler/ hose irrigation system (see http://politics.people.com. cn/GB/1026/3540846.html). However, even raising the efficiency as high as 0.85, irrigation still could not bring the 2070 projected yield to the baseline level for either Baicheng or Tongyu.

\subsubsection{Changing sowing schedules and introducing alternative cultivars}

In response to the future warmer climate, shifting to an earlier sowing date may alleviate the negative effects of high temperature on grain filling, but its effect on maintaining production was not as high as expected. Experiments at the Baicheng site showed that the reduction in 2020 was only offset by $3 \%$ if sowing occurred $8 \mathrm{~d}$ earlier. However, if postponing the sowing date to delay grain filling until late summer or early autumn with the optimal temperature for grain formation, the yield loss could be significantly reduced. By sowing on 10 May, which is 20 d later than the baseline, the production loss at Baicheng could be reduced by 13 and $22 \%$ in 2050 and 2070, respectively.

We also examined the possibility of introducing a new maize cultivar with a longer growth period than the cultivar JilinLate. A spring cultivar from southwest China, Jiao3danjiao (Xiong et al. 2007, with P1 $=320$, $\mathrm{P} 2=0.3, \mathrm{P} 5=900, \mathrm{G} 2=700, \mathrm{G} 3=9.2$, PHINT = 38.9), was experimented with in the western areas of Jilin. To exclude the effect of different G2 and G3 values on yield, we only used P1 and P5 of Jiao3danjiao in this experiment. Without changing the planting schedule, the new cultivar makes more use of the warm climate, and thus has a longer growth season, especially a 1 to 2 wk extension of the grain-filling period, and produces much higher yield in 2020 and 2050 than the baseline level. This indicates that introducing cultivars of southern origin directly is probably a better adaptation option to alleviate the projected reduction in maize production in Jilin than staying with the JilinLate cultivar. 

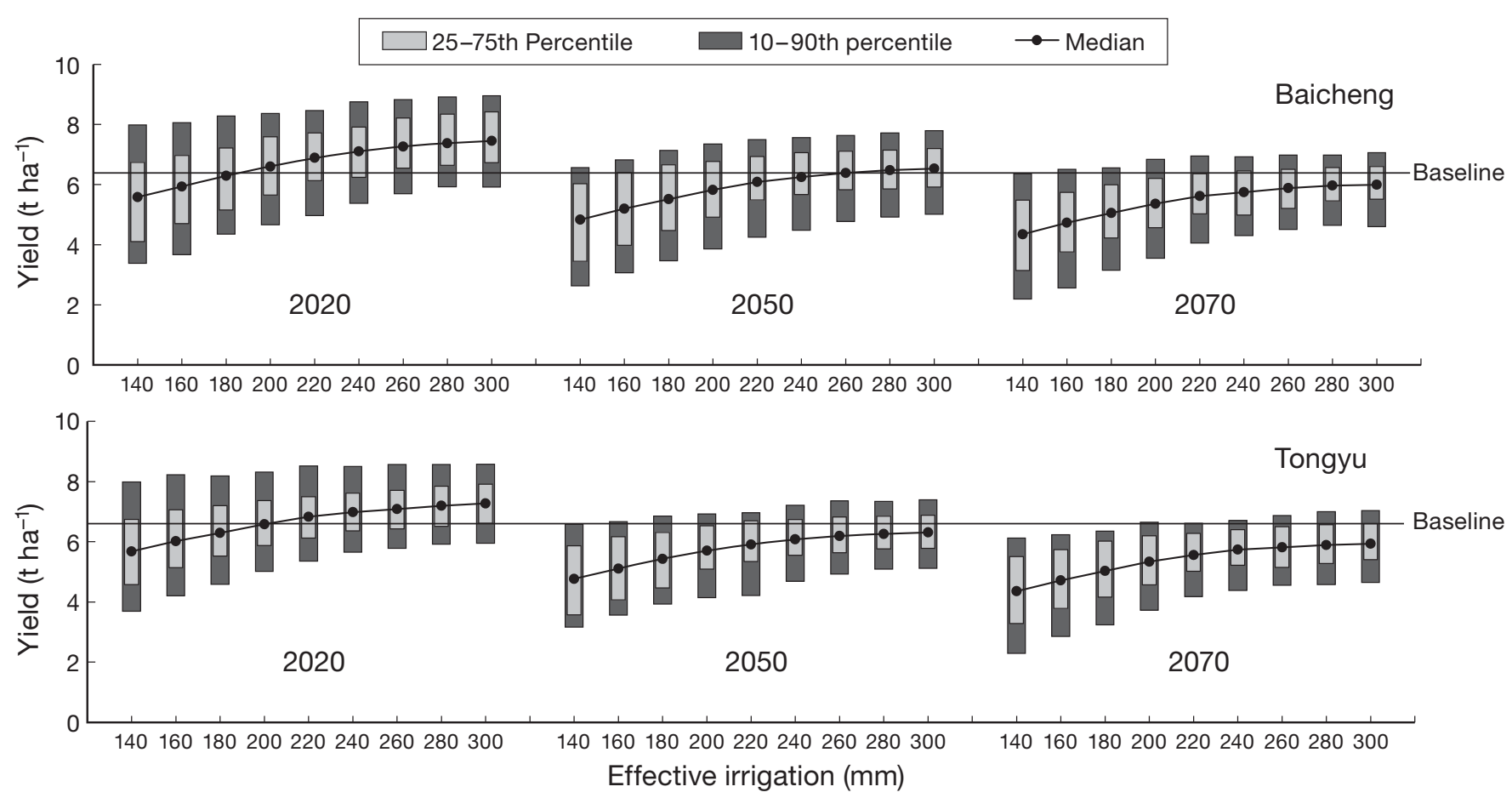

Fig. 9. Effects of increasing effective irrigation on maize yield in Baicheng and Tongyu. The experiments were carried out 100 times for each site under the median climate change scenario

\section{DISCUSSION}

The large sample size of the ensemble approach covered a wide range of GCM internal and inter-model uncertainties and revealed the high uncertainty of climate change in Jilin. Nevertheless, it is very likely that both temperature and precipitation are going to increase, as projected by the majority of the model experiments of the ensemble. However, the precipitation increase cannot offset the land surface water loss due to the intensive thermal variation, which will increase the irrigation insufficiency if the current irrigation supply is maintained (Fig. 8). The arid and semi-arid zones will expand into most parts of the present cropping areas. Furthermore, the changes in thermal resources due to regional warming will accelerate crop growth for the present maize cultivars. The growth period, in particular the grain-filling phase, is projected to be shortened by about 10 to $30 \mathrm{~d}$ in the current main cropping regions (central and western areas), leading to a decreased maize yield. Therefore, the reduction of maize yield in Jilin will keep in step with the global warming trend if current agriculture management is maintained. On the other hand, enhanced $\mathrm{CO}_{2}$ fertilization, or the enhanced $\mathrm{CO}_{2}$ effects on stomatal resistance and photosynthesis, arising from the elevated atmospheric $\mathrm{CO}_{2}$ concentration, might offset the yield reduction significantly, which was also pointed out by previous stud- ies in northeastern China using the CERES model (Jin et al. 1996, Xiong et al. 2007). It is worth noting that such a significant $\mathrm{CO}_{2}$ effect on maize production was only realized for the limited irrigation condition. With sufficient water resources being available through irrigation, the $\mathrm{CO}_{2}$ effect was only about 2 to $3 \%$, which is not as large as the insufficient irrigation experiment. However, in addition to the modeling approach, further detailed field studies are needed to verify the significance of $\mathrm{CO}_{2}$ fertilization on yield under different irrigation regimes. Nevertheless, even with the $\mathrm{CO}_{2}$ fertilization being taken into account, Jilin may still face noticeable risks of reduction in maize yield due to the impacts of climate change.

It is thus evident that the 2 main adaptation measures would be to increase the irrigation efficiency and to change the maize cultivar. The improvements in irrigation facility can provide a better water supply for crops and help maintain the current yield, but they become less effective during the second half of this century. For the semi-arid region, the improvement of irrigation efficiency to 0.55 in 2020 is necessary in order that the present irrigation quota can still satisfy the water demand in maintaining the baseline yield level; otherwise there may be a high risk of reduction in maize production. After the 2050s, even a welldeveloped irrigation system with an efficiency as high as 0.85 cannot maintain the maize yield at the current 
level in the absence of other adaptations. The other adaptation of switching to new maize cultivars that would suit the changed thermal conditions was also tested. As the maturity period of the current cultivar is likely shortened by 20 to $30 \mathrm{~d}$ in the coming decades, alternative cultivars that have a longer grain-filling stage should be introduced, since grain-filling plays a primary role in yield. Compared to optimizing irrigation strategies, the option of cultivar switching is likely to be a long-term adaptation. A final adaptation option might be switching to different crops. However, the effects would rely heavily on the practicability of technique transformation, which is beyond the scope of this study.

The overall changes in eastern humid areas are projected to have more favorable effects on maize yield due to the improved thermal conditions, except for small areas among the present maize-planted areas (e.g. in some areas of Yanji and western Tonghua in Fig. 5). This may suggest that the cultivar used in the eastern area has considerable thermal potential in most parts of eastern Jilin where maize is not the main crop at the current time (maize constitutes $<5 \%$ of total sown area). However, the gains might be weakened in the late part of this century. As shown in Fig. 6, the A1 group scenarios projected a yield decline for Yanji in 2070 compared to 2050, and similarly for Baishan.

Compared to the yield variation among $20 \mathrm{GCMs}$, the difference among projections under the 6 emission scenarios was much smaller (Fig. 6). It is clear that the uncertainties of the impacts on crops mainly arise from the GCMs selected to simulate the future climate changes, and thus any results based on single GCM projections should be interpreted carefully in impact assessments. The disparity in the projected yield among 20 GCMs under A1FI (which is characterized by intensive global warming) was quite large compared to that under the other SRES. This was especially true in Baishan and Yanji, where the yield simulations by some GCMs (CSIR0-30, GISS-ER, IPSL_CM4, UKHADCM3) in 2070 were even lower than the baseline level, deviating from most of the projections of the 120 runs. This raises a question of the conformity of multi-GCM simulations under high global temperatures.

There are limitations of this study due to the data availability, as well as our current understanding of the biophysical processes of maize growth. Firstly, the observation data of maize growth and weather were obtained from those sites located in the main cropping areas of maize, thus in calibration and validation, the cultivar information in minor maize areas was not included. This may induce simulation biases in areas where maize productivity has growth potential and may be the reason why such increases were projected in yield and grain-filling periods in the minor maize areas. Secondly, more soil samples are needed to validate the WISE soil dataset. Several soil parameters required by DSSAT are not included in WISE and hence were estimated from other data sources, or were defaulted to best guess values. More validations of soil data for crop models are required.

Finally, the focus of this study was on the changes in long-term mean maize production and the uncertainties under impacts of climate change. Due to the limits of the crop model and the climate dataset we used, the potential effects related to changes in climate variability were not considered. For example, extremes, such as droughts and floods, may result in a crop-production shock events at an annual or inter-annual timescale. Consequently, predictions of maize yield change and corresponding adaptation options suggested in this study are only applicable to average conditions at the decadal scale.

\section{CONCLUSION}

In this study, we demonstrated an approach for both qualitative and quantitative analysis of the effects of climate change on maize at the regional scale using ensemble climate scenarios derived from 20 GCMs and 6 emission scenarios.

With no alteration in cultivar or cropping techniques, maize yield was projected to decline on average by about 10 to $30 \%$ of the current yield in the central plain and western regions of Jilin Province, but to increase in the current marginal area of the eastern counties under climate conditions in the years 2050 and 2070. The yield reduction in the main cropping area was a response to the combined effect of temperature and precipitation changes on potential water supply and maize phenology. The maize growth season in the major planting regions may be shortened by 15 to $20 \mathrm{~d}$ in 2070, with a significant drop in the grain-filling period. Although there may be a moderate improvement in maize production in eastern regions, where it is not the major production region, the yield reduction of the whole province could be quite substantial in the coming decades and could have serious implications for local, and even national, food security. In 2070, we predict a $>90 \%$ probability of a $15 \%$ reduction in Jilin maize yield based on the ensemble results.

We identified improvement of irrigation and crop cultivar shifting as the 2 major adaptation options. The increasing dryness of the main maize growing area can be alleviated by increasing irrigation. With doubling of the total irrigation, the maize yield in the arid west would maintain the baseline level up to the year 2050, but the improvement in irrigation will become 
less effective towards the second half of this century. Combined adaptation measures for optimising irrigation and switching cultivars are required to keep the current maize yield level unchanged. Further studies are needed on the individual and interactive effects of irrigation strategy, cultivar alteration, and other adaptation options in future cultivation.

In summary, this study illustrates a method for providing useful information on the impacts of climate change on food security and adaptation options for local policy makers based on risk assessment. It demonstrates a spatial application of an originally sitebased crop production model to simulate the effects of climate change on yield, working grid cell by grid cell, rather than following the common representative site approach. Depending on data availability, such a method provides a potentially more accurate simulation for each grid cell, thereby resulting in significantly improved confidence in a regional assessment when results are obtained from spatial aggregation of the grid cells for the given region.

Acknowledgements. This research was supported by the Asia Pacific Network for Global Change Research (APN) CAPaBLE project, CRP2008-02CMY. Four anonymous reviewers and the editor provided valuable comments on the manuscript.

\section{LITERATURE CITED}

Batjes NH (2006) ISRIC-WISE derived soil properties on a 5 by 5 arc-minutes global grid. Report 2006/02 (with data set). ISRIC-World Soil Information, Wageningen. Available at www.isric.org

Braga RP, Cardoso MJ, Coelho JP (2008) Crop model based decision support for maize (Zea mays L.) silage production in Portugal. Eur J Agron 28:224-233

Covey C, AchutaRao KM, Cubasch U, Jones PD and others (2003) An overview of results from the Coupled Model Intercomparison Project. Global Planet Change 37: 103-133

Cui Q (2005) The evaluation on the affection of the future climate change on the maize production in China. MSc thesis, Chinese Agricultural University, Beijing (in Chinese)

Gijsman AJ, Jagtap SS, Jones JW (2002) Wading through a swamp of complete confusion: how to choose a method for estimating soil water retention parameters for crop models. Eur J Agron 18:77-106

Gijsman AJ, Thornton PK, Hoogenboom G (2007) Using the WISE database to parameterize soil inputs for crop simulation models. Comput Electron Agric 56:85-100

Gungula DT, Kling JG, Togun AO (2003) CERES-Maize predictions of maize phenology under nitrogen-stressed conditions in Nigeria. Agron J 95:892-899

Hoogenboom G, Tsuji GY, Pickering NB, Curry RB, Jones JJ, Singh U, Godwin DC (1995) Decision support system to study climate change impacts on crop production. In: Rosenzweig C, Allen LH Jr, Harper LA, Hollinger SE, Jones JW (eds) Climate change and agriculture: analysis of potential international impacts. ASA Special Publication No. 59, Madison, WI, p 51-75
Hoogenboom G, Jones JW, Wilkens PW, Porter CH and others (2004) Decision support systems for agrotechnology transfer, version 4.0. CD-ROM. University of Hawaii, Honolulu, $\mathrm{HI}$

Hulme M, Carter T (1999) Representing uncertainty in climate change scenarios and impact studies. In: Carter TR, Hulme M, Viner D (eds) Proc ECLAT-2 Helsinki workshop 14-16 April. Climatic Research Unit, UEA, Norwich, p $11-37$

Iglesias A (2006) Use of DSSAT models for climate change impact assessment: calibration and validation of CERESWheat and CERES-Maize in Spain. In: Utset A (ed) Climate variability, modelling tools and agricultural decisionmaking. Proc CGE Hands-on Training Workshop on V\&A Assessment of the Asia and the Pacific Region. Nova Science Publishers, New York, NY

IPCC (Inter-governmental Panel on Climate Change) (2000) Special report on emissions scenarios: a special report of Working Group III of the Inter-governmental Panel on Climate Change. Cambridge University Press, New York, NY

IPCC-TGICA (2007) General guidelines on the use of scenario data for climate impact and adaptation assessment. Version 2. Task Group on data and scenario support for impact and climate assessment, Inter-governmental Panel on Climate Change. www.ipcc-data.org/guidelines/TGICA _guidance_sdciaa_v2_final.pdf

Jin ZQ, Ge DK, Zheng XL, Chen H (1996) Assessing the potential impacts of global climate change on maize production in China. Acta Agronom Sin 22:513-524 (in Chinese)

Jin ZQ, Ge DK, Shi C, Gao L (2002) Several strategies of food crop production in the Northeast China Plain for adaptation to global climate change. Acta Agronom Sin 28:24-31

> Jones PG, Thornton PK (2003) The potential impact of climate change on maize production in Africa and Latin America in 2055. Glob Environ Change 13:51-59

Jones JW, Hoogenboom G, Porter CH, Boote KJ and others (2003) The DSSAT cropping system model. Eur J Agron 18:235-265

Katz RW (2002) Techniques for estimating uncertainty in climate change scenarios and impact studies. Clim Res 20: 167-185

Kimball BA (1983) Carbon dioxide and agricultural yield: an assemblage and analysis of 430 prior observations. Agron J 75:779-788

- Leakey ADB, Uribelarrea M, Ainsworth EA, Naidu SL, Rogers A, Ort DR, Long SP (2006) Photosynthesis, productivity and yield of maize are not affected by open-air elevation of $\mathrm{CO}_{2}$ concentration in the absence of drought. Plant Physiol 140:779-790

Leakey ADB, Ainsworth EA, Bernacchi CJ, Rogers A, Long $\mathrm{SP}$, Ort DR (2009) Elevated $\mathrm{CO}_{2}$ effects on plant carbon, nitrogen and water relations: six important lessons from FACE. J Exp Bot 60:2859-2876

Leff B, Ramankutty N, Foley JA (2004) Geographic distribution of major crops across the world. Global Biogeochem Cycles 18:GB1009

Li Y, Ye W, Wang M, Yan X (2009) Climate change and drought: a risk assessment of crop-yield impacts. Clim Res 39:31-46

Luo X, An J, Liu X (2000) Heat index of maize growth and development, and distribution of variety types. J Shenyang Agric Univ 31:318-323 (in Chinese)

Ma ZG, Huang G, Gan W, Chen M (2005) Multi-scale temporal characteristics of the dryness/wetness over northern China during the last century. Chin J Atmos Sci 29:671-681 (in Chinese) 
Maytín CE, Acevedo MF, Jaimez R, Andressen R, Harwell MA, Robock A, Azócar A (1995) Potential effects of global climatic change on the phenology and yield of maize in Venezuela. Clim Change 29:189-211

Mitchell TD (2003) Pattern scaling: an examination of the accuracy of the technique for describing future climates. Clim Change 60:217-242

Mitchell TD, Jones PD (2005) An improved method of constructing a database of monthly climate observations and associated high-resolution grids. Int J Climatol 25:693-712

Mitchell JFB, Johns TC, Eagles M, Ingram WJ, Davis RA (1999) Towards the construction of climate change scenarios. Clim Change 41:547-581

Naylor RL, Battisti DS, Vimont DJ, Falcon WP, Burke MB (2007) Assessing risks of climate variability and climate change for Indonesian rice agriculture. Proc Natl Acad Sci USA 104:7752-7757

New M, Hulme M (2000) Representing uncertainty in climate change scenarios: a Monte-Carlo approach. Integr Assess 1:203-213

New M, Lister D, Hulme M, Makin I (2002) A high-resolution data set of surface climate over global land areas. Clim Res 21:1-25

O'Neal MR, Frankenberger JR, Ess DR (2002) Use of CERESMaize to study effect of spatial precipitation variability on yield. Agric Syst 73:205-225

Parry M, Rosenzweig C, Iglesias A, Fischer G, Livermore M (1999) Climate change and world food security: a new assessment. Global Environ Change, 9(S1):S51-S67

Parzen E (1962) On estimation of a probability density function and mode. Ann Math Stat 33:1065-1076

Ruosteenoja K, Tuomenvirta H, Jylha K (2007) GCM-based regional temperature and precipitation change estimates for Europe under four SRES scenarios applying a super-ensemble pattern-scaling method. Clim Change 81:193-208

Santer BD, Wigley TML (1990) Regional validation of means, variances and spatial patterns in general circulation model control runs. J Geophys Res 95:829-850

Saxton KE, Rawls WJ (2006) Soil water characteristic estimates by texture and organic matter for hydrologic solutions. Soil Sci Soc Am J 70:1569-1578

Saxton KE, Rawls WJ, Romberger JS, Papendick RI (1986) Estimating generalized soil-water characteristics from texture. Soil Sci Soc Am J 50:1031-1036

Soler CMT, Sentelhas PC, Hoogenboom G (2007) Application of the CSM - CERES-Maize model for planting date evaluation and yield forecasting for maize grown off-season in a subtropical environment. Eur J Agron 27:165-177

Song YB, Wang JL, Yang FY (2006) Food security and meteorological service. China Meteorological Press, Beijing (in Chinese)
Su W, Liu JS (2006) Analysis of the water resource problems and its counter measures of sustainable utilization in Jilin province. J Anhui Agri Sci 34:5943-5945 (in Chinese)

> Tao F, Hayashi Y, Zhang Z, Sakamoto T, Yokozawa M (2009) Global warming, rice production, and water use in China: developing a probabilistic assessment. Agric For Meteorol 149:1266-1278

Tebaldi C, Lobell DB (2008) Towards probabilistic projections of climate change impacts on global crop yields. Geophys Res Lett 35:L08705 doi:10.1029/2008GL033423

Tong C, Zhang W, Tang Y, Wang H (2005) Estimation of daily solar radiation in China. Chin J Agrometeorol 26:165-169 (in Chinese)

Torriani D, Calanca P, Lips M, Ammann H, Beniston M, Fuhrer J (2007) Regional assessment of climatic change impacts on maize productivity and associated production risk in Switzerland. Reg Environ Change 7:209-221

Vera-Diaz MC, Kaufmann RK, Nepstad DC, Schlesinger P (2008) An interdisciplinary model of soybean yield in the Amazon Basin: the climatic, edaphic and economic determinants. Ecol Econ 65:420-433

Wigley TML (2003) MAGICC/SCENGEN 4.1: technical manual. National Center for Atmospheric Research, Boulder, CO. Available at: www.cgd.ucar.edu/cas/wigley/magicc/

Wu Y, Sakamoto CM, Botner DM (1989) On the application of the CERES-maize model to the North China Plain. Agric For Meteorol 49:9-22

Xiong W, Xu Y, Lin E, Lu Z (2005) Regional simulation of maize yield under IPCC SRES A2 and B2 scenarios. Chin J Agrometeorol 26:11-15 (in Chinese)

> Xiong W, Matthews R, Holman I, Lin E, Xu Y (2007) Modelling China's potential maize production at regional scale under climate change. Clim Change 85:433-451

> Xiong W, Holman I, Conway D, Lin E, Li Y (2008) A crop model cross calibration for use in regional climate impacts studies. Ecol Model 213:365-380

Xu D, Kang SZ (2002) Research progress and development trend on modernized agriculture water-saving technology. High Techno Lett 12:103-108 (in Chinese)

Yang Y, Watanabe M, Zhang X, Zhang J, Wang Q, Hayashi S (2006) Estimation of groundwater use by crop production simulated by DSSAT-wheat and DSSAT-maize models in the piedmont region of the North China Plain. Hydrol Process 20:2787-2802

Yu Q, Saseendran SA, Ma L, Flerchinger GN, Green TR, Ahuja LR (2006) Modelling a wheat-maize double cropping system in China using two plant growth modules in RZWQM. Agric Syst 89:457-477

Zhang Y, Ma Y, Liao S (2004) Method of optimizing maize variety parameters in the CERES-maize simulation model. J Chin Agric Univ 9:24-29 (in Chinese) 
Appendix 1. Additional information

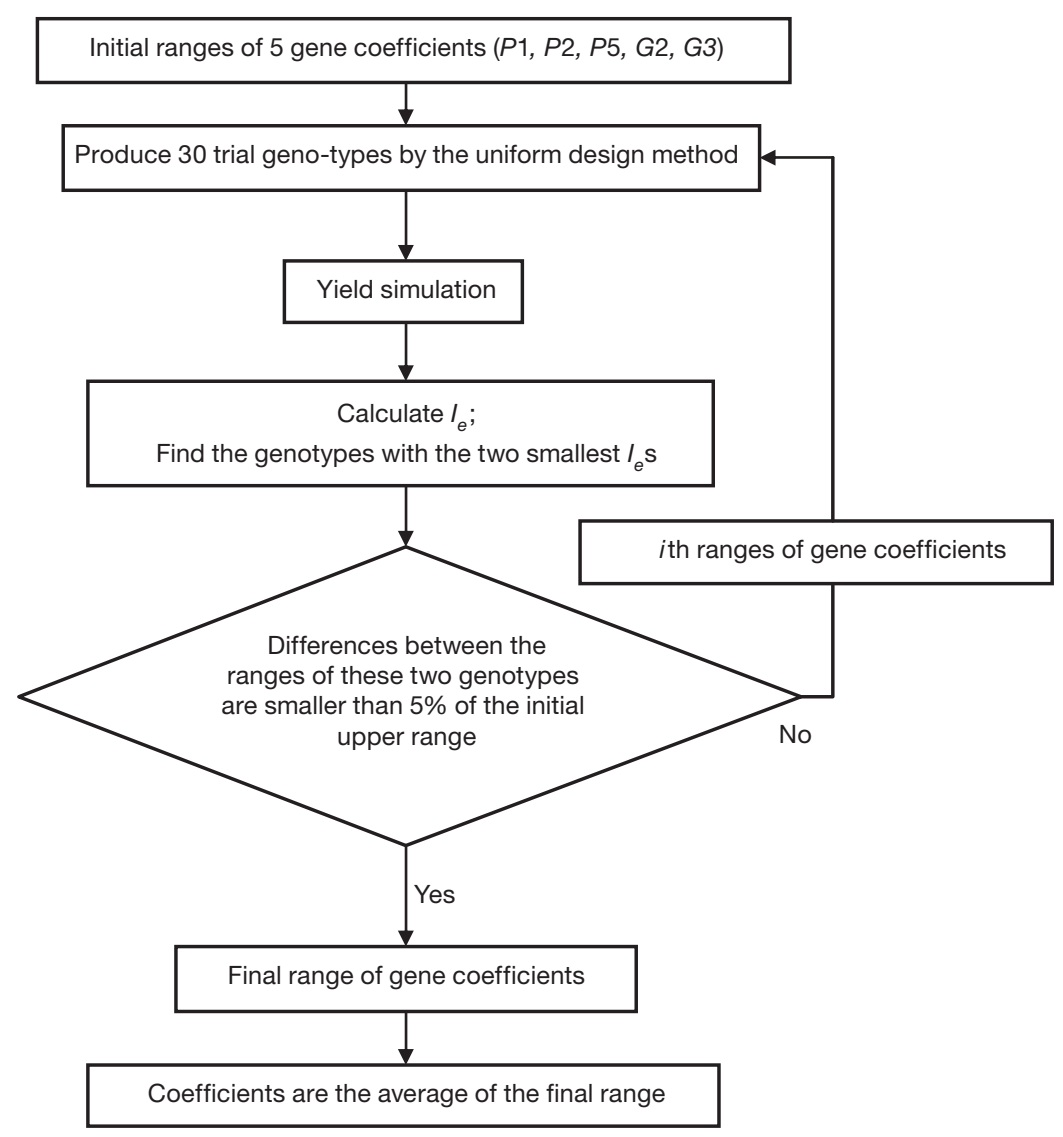

Fig. A1. Iteration procedure to optimize the maize cultivar genotype. $I_{e}$ : evaluating indicator (see Section 2.4. in main text)

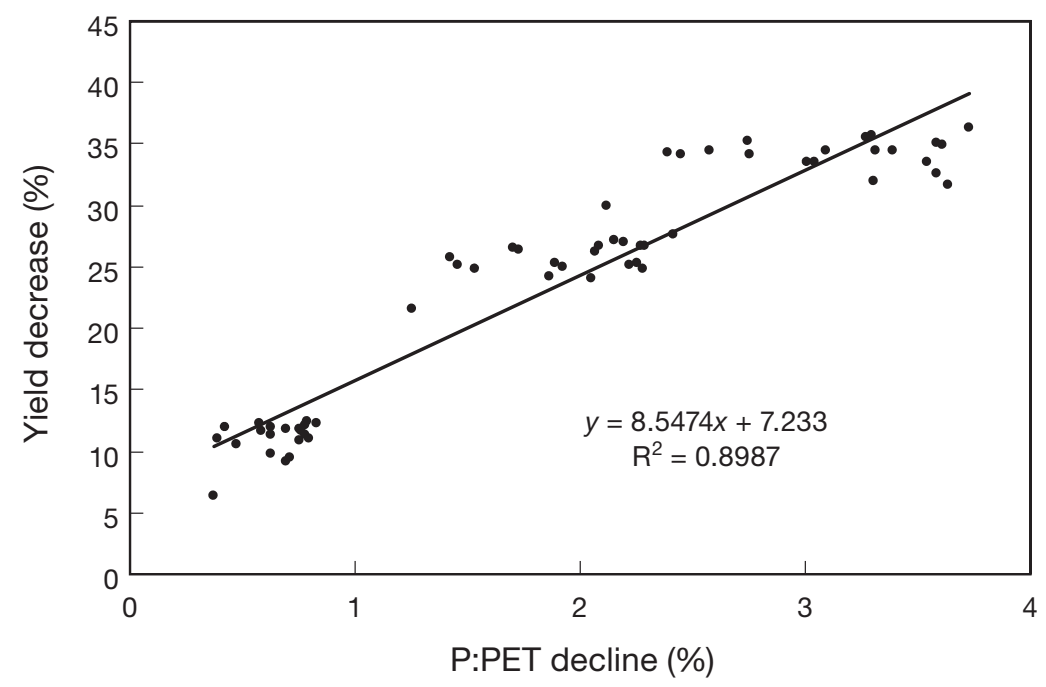

Fig. A2. Change in maize yield responding to a future decline in the precipitation to potential evaporation ratio (P:PET) during the growing season (April to September) in Baicheng, Songyuan, Changchun, and Siping. Yield change (dots) is aggregated at the county scale 

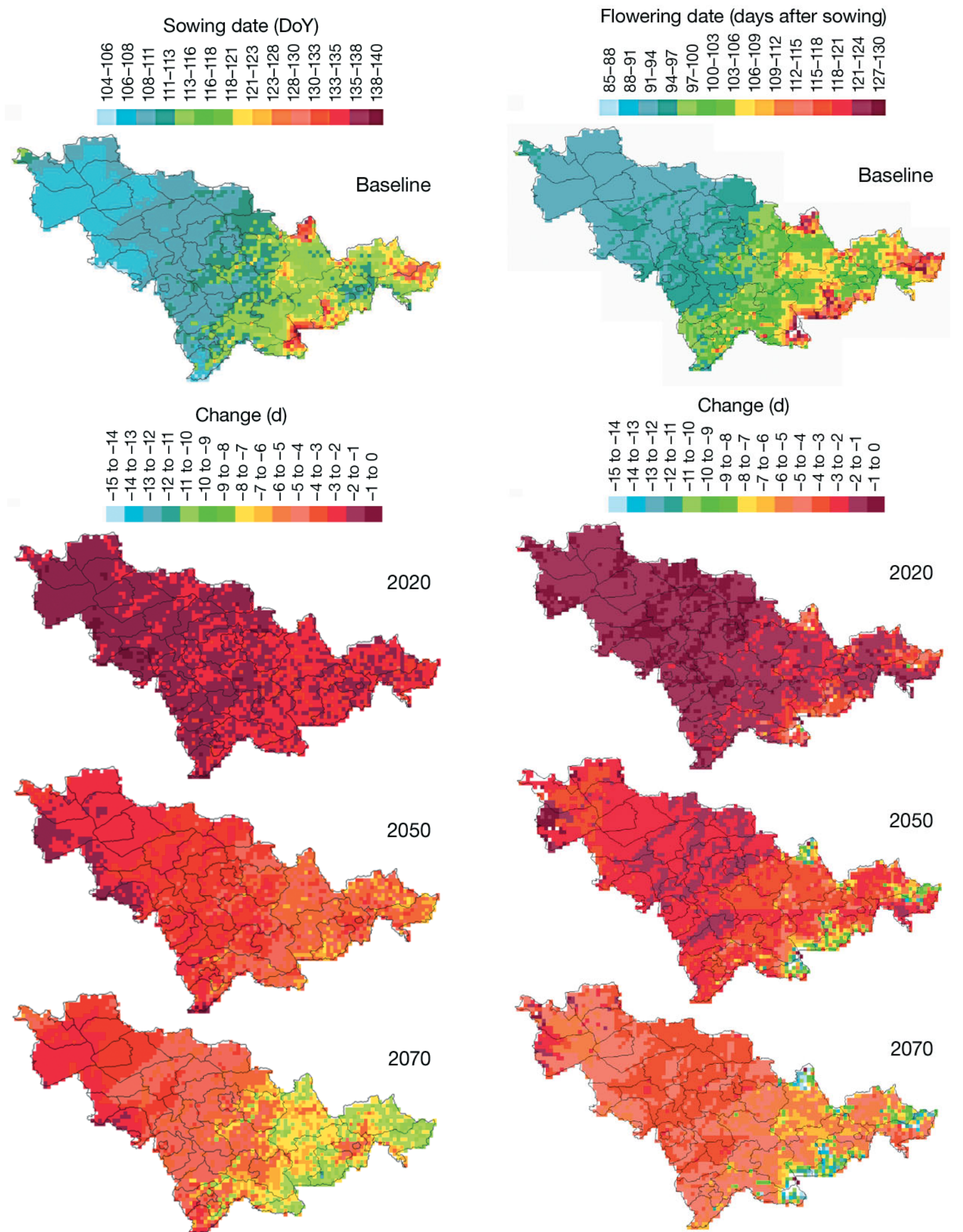

Fig. A4. Simulated flowering date (days after sowing) at

Fig. A3. Maize sowing date at baseline and its changes in 2020, 2050, and 2070. DoY: day of year; negative values: advance date baseline and its probable advances in 2020, 2050, and 2070. Negative values: earlier days 

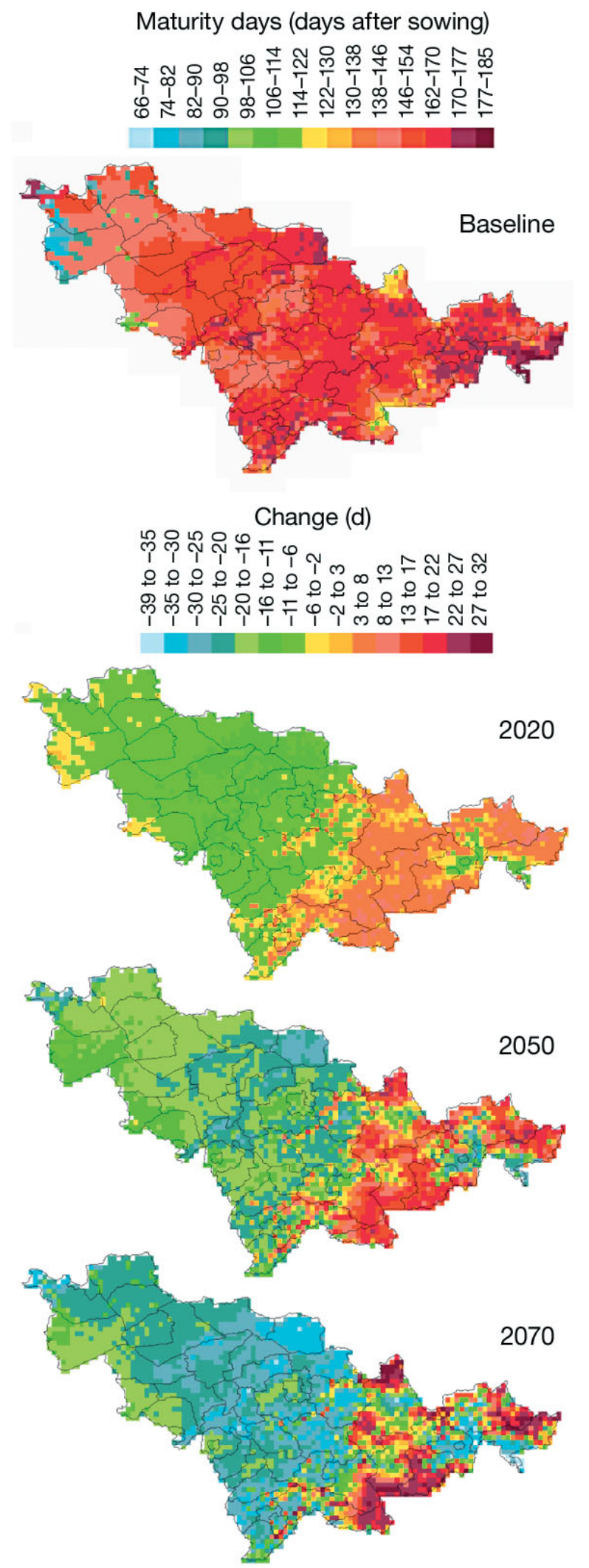

Fig. A5. Simulated number of maturity days (days after sowing) at baseline and its probable advances in 2020, 2050, and 2070. Negative values: earlier days 